\title{
Efeitos das políticas de inovação nos gastos com atividades inovativas das pequenas empresas brasileiras
}

\author{
Ana Paula Macedo de Avellar \\ Professora - Universidade Federal de Uberlândia (UFU) \\ Endereço: Av. João Naves de Ávila, 2121 - Bloco J - Sala 1J 256 - Campus Santa Mônica \\ Uberlândia - MG - CEP: 38408-144 - E-mail: anaavellar@ufu.br

\section{Marisa dos Reis Azevedo Botelho} \\ Professora - Universidade Federal de Uberlândia (UFU) \\ Endereço: Av. João Naves de Ávila, 2121 - Bloco J - Sala 1J 254 - Campus Santa Mônica \\ Uberlândia/MG - CEP: 38408-144 - E-mail: botelhomr@ufu.br
}

Recebido: 22/08/2014. Aceito 04/05/2016.

\section{Resumo}

O objetivo deste artigo é realizar, de forma pioneira, uma análise dos impactos dos programas de apoio às atividades inovativas nas pequenas empresas brasileiras. Utiliza-se o método Propensity Score Matching para avaliar os impactos dos incentivos fiscais, dos programas de financiamento, da concessão de bolsas e de capital de risco, com microdados da PINTEC (2010). Os resultados apontam que o conjunto dos programas de apoio à inovação estimula os gastos com atividades inovativas das pequenas empresas. Dentre os programas, os que se mostraram mais efetivos foram os de financiamento e os de apoio à aquisição de máquinas e equipamentos.

\section{Palavras-Chave}

Avaliação de impacto. Política de inovação. Pequenas empresas. Propensity Score Matching.

\begin{abstract}
This paper analyses, for the first time, the impact of the supporting programs concerning innovative activities in Brazilian small firms. Using the Propensity Score Matching technique with the PINTEC database (2010), we analyze the impacts of the tax incentives, grants, financing, RHAE and venture capital programs. The conclusion of the empirical study is that the innovation-oriented supporting programs, as a whole, accomplish the task of increasing the Brazilian small firms spending with innovative activities. Studying each program in particular, the conclusion is that the most effective ones are the general financing programs and the programs that support the purchase of machinery and equipments.
\end{abstract}

\section{Keywords}

Impact evaluation. Innovation policy. Small firms. Propensity Score Matching.

\section{JEL Classification}

O32. O38. C31. L25.

- Agradecimentos ao apoio da Fundação de Amparo à Pesquisa de Minas Gerais (Fapemig) e aos pareceristas, cujos comentários contribuíram para aprimorar o trabalho. 


\section{Introdução}

Desde o início dos anos 2000, tem-se um conjunto de mudanças político-institucionais voltado ao estímulo às atividades inovativas das empresas brasileiras. Estas mudanças se consubstanciam em um novo regime de incentivos fiscais (Lei do Bem), em novos programas de apoio financeiro (por meio da Financiadora de Estudos e Projetos - FINEP e Banco Nacional de Desenvolvimento Econômico e Social - BNDES, principalmente) e em estímulos às parcerias entre empresas e outros agentes do sistema de inovações, em particular as universidades e centros de pesquisa (operados pela FINEP, Serviço Brasileiro de Apoio às Micro e Pequenas Empresas - SEBRAE e instituições de cunho estadual). Novos programas foram viabilizados por mudanças na legislação, com a implementação da Lei de Inovação, como é o caso dos programas de subvenção econômica.

Parte dos programas de estímulo às atividades inovativas direcionam-se para as empresas de pequeno porte, ${ }^{l}$ seguindo uma tendência comum a países desenvolvidos e em desenvolvimento (OECD, 2010; Dini e Stumpo, 2011). Dentre os fatores que contribuem para a proliferação de programas voltados a estas empresas estão a sua importante participação nas estruturas produtivas e na geração de empregos, assim como a contribuição para a geração de inovações superior à prevista pelos primeiros trabalhos acadêmicos dedicados a este tema. ${ }^{2}$ Os programas de apoio são desenhados de modo a con-

1 A definição de porte das empresas não respeita um critério universalmente aceito. Em geral, utilizam-se critérios de faturamento e/ou de número de empregados para classificar as empresas segundo o porte. Em relação ao número de empregados, nos países europeus consideram-se pequenas e médias empresas as que possuem até 250 empregados. Nos Estados Unidos, considera-se o limite de 500 empregados para denominar as pequenas e médias empresas. Nos países em desenvolvimento é comum o foco das políticas recair sobre as denominadas micro e pequenas empresas que, no caso da indústria brasileira, englobam empresas com até 99 empregados, seguindo a classificação do SEBRAE. Utiliza-se a denominação genérica de pequenas empresas (PEs) para referir-se ao segmento de empresas que possuem até 99 empregados, que constitui o foco do presente trabalho.

2 Os estudos de Scherer (1965) e Comanor (1967) tentaram inicialmente verificar a validade das hipóteses levantadas em fases distintas da obra de J. Schumpeter, a saber: a fase identificada como Schumpeter Marco 1 (SM1), em que o autor realça o papel de empreendedores e das empresas de pequeno porte na geração de inovações, e a fase madura, Schumpeter Marco 2 (SM2), na qual a ênfase recai sobre o papel das grandes empresas e seus laboratórios de P\&D como essenciais para a geração de inovações. Revisões posteriores destes trabalhos, como a de Cohen et al. (1987), somaram-se a outros estudos que apresentaram resultados díspares que corroboram, a depender da metodologia e da base de dados utilizada, as duas hipóteses. O ponto de vista predominante passa a ser o de que a atividade de inovação difere entre grandes e pequenas empresas, especialmente devido ao fato de que as PEs tendem a realizar esforços inovativos menos concentrados em gastos formais de P\&D (Kleinknecht; Reijnen,1991; Santarelli; Piergiovanni, 1996), e que a relação linear entre porte e inovação 
tornar as dificuldades para efetuar atividades inovativas, cujos risco e custo são, em geral, elevados, especialmente para as empresas de pequeno porte que encontram mais dificuldades de acessar o financiamento externo.

Entretanto, dada a heterogeneidade que caracteriza o segmento das pequenas empresas e as especificidades das suas atividades inovativas, há, em geral, um conjunto amplo de programas, desenhados de modo a atender aos diferentes grupos de empresas. Os programas se diferenciam quanto aos instrumentos (incentivos fiscais ou financeiros), quanto ao público-alvo (start ups, empresas já consolidadas) e quanto ao setor de atividade (setores maduros ou de tecnologia de ponta). $\mathrm{Na}$ esteira da proliferação de programas de estímulo às atividades inovativas de empresas de pequeno porte, cresceu também o volume de estudos dedicados à avaliação da efetividade destes programas, em geral, através de análises de impacto realizadas com metodologia econométrica.

O presente artigo insere-se nesta discussão ao realizar, de forma pioneira, análise de impacto dos programas de estímulo aos gastos com atividades inovativas de pequenas empresas (PEs) atualmente em vigência na economia brasileira. Através da comparação de empresas contempladas e não contempladas pelos programas utilizando o método do Propensity Score Matching (PSM), são analisados os impactos da Lei de Informática e Lei do Bem, dos programas de financiamento, de concessão de bolsas (programa RHAE) e de capital de risco, a partir de microdados da PINTEC (Pesquisa de Inovação Tecnológica, 2010). Realiza-se análise conjunta e de cada instrumento separadamente, o que permite identificar suas diferenças de impacto.

Para cumprir este objetivo, o trabalho estrutura-se em cinco seções, além da Introdução e Considerações Finais. A seção 2 dedica-se a uma revisão da experiência internacional de avaliação de políticas de inovação, com foco nos estudos que consideram o porte das em-

prevista em SM2 não se apresenta para todos os setores de atividade (Pavit et al., 1987). Posteriormente, a partir de bases de dados construídas para investigar diretamente a atividade inovativa das empresas (e não mais através de proxies, como gastos em $P \& D$ e patentes), foi possível identificar mais realisticamente a participação das empresas de pequeno porte na atividade de inovação e sua importante participação em certos setores de atividade, como os de instrumentos mecânicos e de engenharia, maquinaria não elétrica, equipamentos elétricos, química e instrumentos (Pavit et al., 1987; Acs e Audretsch, 1990; Tether et al., 1997). Uma síntese destes trabalhos é apresentada em Audretsch (2004). 
presas. Na seção 3, é apresentado um breve histórico da evolução das políticas de apoio às empresas de pequeno porte brasileiras. A seção 4 descreve a metodologia do estudo empírico realizado com a técnica PSM. Na seção 5 encontra-se o núcleo principal do artigo, onde são apresentados os resultados da comparação entre empresas contempladas e não contempladas pelos programas de apoio.

\section{Avaliação de políticas de inovação e algumas experiências internacionais}

Diversos países adotaram, especialmente a partir dos anos 1990, políticas públicas de incentivo à inovação. ${ }^{3} \mathrm{O}$ desenho destas políticas e os instrumentos utilizados para levá-las a cabo variam entre países, mas há, em geral, a combinação de instrumentos de incentivo fiscal e de incentivo financeiro (empréstimos subsidiados, subvenção econômica, entre outros). O objetivo é estimular os gastos privados em pesquisa e desenvolvimento (P\&D) e em outras atividades inovativas, promovendo a redução dos custos envolvidos, tanto de maneira direta, através de empréstimos subsidiados e recursos diretamente aplicados, ou indiretamente, através de medidas de cunho fiscal.

Os estudos com o propósito geral de avaliar a efetividade das políticas públicas de apoio à inovação apresentam metodologias diversas. Entretanto, nos últimos anos verifica-se a predominância de estudos que utilizam técnicas econométricas, a fim de comparar grupos de empresas contempladas pelos programas com grupos que apresentam características semelhantes, ou possibilidades semelhantes de terem sido selecionadas como objeto de apoio, de modo a apreender a efetividade das políticas públicas.

3 Políticas públicas voltadas ao setor produtivo com foco na inovação têm evoluído de forma marcante, mas com grandes diferenças entre os países, conforme atesta a abrangente síntese apresentada por Lundvall e Borrás (2006). Os autores mostram que, no caso dos países europeus, é possível verificar a sistematização de ações voltadas ao apoio de atividades científicas e tecnológicas desde os anos 1960, que culminam com a denominada Agenda de Lisboa (2000), que estabelece parâmetros para a ação dos países membros para as duas décadas seguintes. Documentos elaborados no âmbito da OECD mostram como os diversos países membros têm voltado crescentemente suas ações para o estímulo à inovação, a exemplo da série Science, Technology and Industry Outlook, publicada desde 2002. 
A análise dos efeitos destas políticas apresenta resultados divergentes, embora a maior parte deles conclua pela predominância do "efeito additionality" (complementaridade entre gastos públicos e privados) e pela negação da hipótese de "crowding out" (substituição entre o gasto público e privado). Nesta linha, podem ser citados os trabalhos de Leyden e Link (1993), que analisam quatro países (Estados Unidos, Japão, Canadá e Suécia), com dados de 1987; Hall e Van Reenen (2000), que comparam a utilização de instrumentos de incentivos fiscais e de financiamento para vários países da OECD, concluindo que os incentivos fiscais são mais eficientes para estimular os gastos privados de P\&D; Bloom et al. (2002), que desenvolvem análise específica sobre os efeitos da política de incentivos fiscais em nove países da OCDE para o período de 1974 a 1994; Aerts e Czarnitzki (2004), para o caso específico da Bélgica e utilizando-se da base de dados da Community Innovation Survey (CIS) de 2001; Benavente et al. (2012), focado no caso chileno.

Como parte dos trabalhos identificou efeitos de substituição e inibição de gastos privados em função dos subsídios públicos (crowding out), ${ }^{4}$ alguns estudos empreenderam ampla revisão dos resultados encontrados na literatura internacional. A primeira grande revisão foi a empreendida por David et al. (2000). Dos 19 estudos analisados pelos autores, nove encontram "efeito crowding out", ou seja, a substituição entre o gasto público e privado, e dez encontram "efeito additionality", compreendido como a presença de complementaridade entre gastos públicos e gastos privados. Os resultados desta revisão são inconclusivos, mas cabe a ressalva de que a maior parte dos trabalhos analisados utiliza metodologias diferentes (análise custo-benefício, mínimos quadrados ordinários, Propensity Score Matching (PSM), modelos de Heckman), e aqueles que identificam a presença de crowding out concentram-se no comportamento das empresas atuantes nos Estados Unidos, principalmente do setor de defesa desse país (o que pode indicar algum efeito setorial, cuja análise foge ao escopo do presente trabalho).

\footnotetext{
4 É caso do estudo de Wallsten (2000), que avaliou o impacto do programa de financiamento estadunidense Small Business Innovation Research Program (SBIR) entre os anos 1990 e 1992. Entretanto, outros estudos que analisaram este programa, incluindo a avaliação pioneira realizada por Lerner (1996), identificaram efeitos positivos dos subsídios públicos, o que influenciou na definição de programas similares implementados em outros países.
} 
Um trabalho recente elaborado por Acevedo e Tan (2010) para o Banco Mundial também realizou revisão dos principais resultados encontrados por estudos especificamente dedicados à avaliação dos impactos de políticas públicas voltadas ao apoio à $\mathrm{P} \& \mathrm{D}$, empreendidas entre o final dos anos 1990 e o início dos anos 2000. A revisão considerou apenas resultados obtidos por estudos econométricos que comparam empresas contempladas pelo apoio público e grupos de controle, o que resultou na seleção de 19 estudos para países desenvolvidos e em desenvolvimento, tornando esta revisão mais abrangente do que a de David et al. (2000), que só considera países desenvolvidos.

Dentre os resultados encontrados, os mais positivos referem-se a variáveis de esforço inovativo: aumento de gastos em P\&D e em treinamento de trabalhadores, introdução de novos processos produtivos e práticas de controle de qualidade, formação de redes de empresas e acesso a novas fontes de informação. Resultados mais ambíguos, e mais concentrados nos países em desenvolvimento, foram encontrados em variáveis de desempenho, como crescimento de produção, vendas e exportação, investimento, emprego, probabilidade de sobrevivência e produtividade. Acevedo e Tan (2010) entendem que uma possível explicação para este resultado decorre do fato de os programas em vigência nos países em desenvolvimento serem relativamente mais recentes que os analisados para os países desenvolvidos, dificultando a obtenção de resultados que necessitam de prazos mais longos para se concretizarem.

Quando se considera o segmento das PEs, foco de grande parte dos programas atualmente em vigência em diversos países ${ }^{5}$ e objeto principal deste trabalho, os estudos, embora mais escassos, têm aumentado nos últimos anos. A análise destes estudos encontra dificuldades decorrentes, em primeiro lugar, da ausência de um critério único que defina o que são pequenas empresas, tornando maior a dificuldade

5 Dentre os países da OECD, esta tendência se verifica desde os anos 1980 (OECD, 1993) e, para os países europeus, tornou-se mais explícita a partir do Small Business Act, instituído em 2008, que reconhece o papel central das PEs na economia europeia e parte da premissa 'think small first' (Eurostat, 2011). Para os países da América Latina, somente nos anos 2000 têm-se ações de política mais articuladas voltadas às empresas de pequeno porte. Consultar Revest e Sapio (2012) para uma síntese e avaliação dos programas voltados a pequenas empresas de base tecnológica atualmente vigentes nos países europeus. Para os países da América Latina, consultar Acevedo e Tan (2010), Dini e Stumpo (2011) e Ferraro (2011). Para o Brasil, Matos e Arroio (2011) apresentam uma síntese dos programas em vigência atualmente. Outros estudos voltados a países específicos são apresentados na sequência do artigo. 
de se comparar os resultados encontrados, mesmo quando os procedimentos metodológicos são similares. Outra dificuldade diz respeito ao fato de os programas implementados em países em desenvolvimento serem mais recentes, o que dificulta apreender os efeitos dos programas que, em geral, apresentam-se em prazos mais longos.

Os resultados de estudos que, de alguma maneira, consideraram a questão do porte são apresentados na sequência. O primeiro estudo dedicado à análise dos efeitos de programas de apoio à $\mathrm{P} \& \mathrm{D}$ em empresas de pequeno porte foi o de Lerner (1996), que analisou um dos programas mais antigos e conhecidos, o Small Business Innovation Research (SBIR), implementado no âmbito do Small Business Innovation Development Act (1982) nos Estados Unidos. O SBIR tem como objetivo principal estimular as inovações tecnológicas nas pequenas empresas privadas (menos de 500 empregados) e o surgimento de novas empresas de base tecnológica. Lerner (1996) compara o desempenho de empresas contempladas pelo programa vis-à-vis empresas não contempladas através de resultados de evolução das vendas e do emprego. A principal conclusão da avaliação realizada é a de que "the SBIR awardees enjoyed substantially greater employment and sales growth, but these effects were confined to firms in areas that attracted significant venture financing." (p. 22). Portanto, além de realçar os resultados positivos alcançados pelas empresas beneficiadas pelos subsídios, verificou-se também o efeito da localização geográfica, com uma concentração dos recursos em áreas onde há intensa atividade de pesquisa e ambiente de forte empreendedorismo. Há ainda outras conclusões importantes do estudo, como a de que mesmo desconsiderando a importância dos recursos financeiros do Programa, o sinal dado pela aprovação do recurso pelo órgão responsável qualifica a inovação em pauta, aspecto assinalado pelas empresas que tiveram seus projetos aprovados. ${ }^{6}$

Lach (2002) apresenta avaliação dos subsídios para P\&D de firmas industriais de Israel para o período 1990-99, implementados pelo Office of the Chief Scientist, órgão do Ministério da Indústria e Comércio. Por meio do uso de Difference-in-difference estimators (DiD) e modelos dinâmicos de dados em painel, o autor compara

6 Outras avaliações do SBIR foram efetuadas por Elston e Audretsch (2009) e Allen et al. (2012). Estes estudos diferem quanto aos objetivos, período de análise e metodologia utilizada, mas avaliam positivamente os efeitos dos gastos públicos. Enquanto Elston e Audretsch (2009) concluem sobre o papel do SBIR para a abertura de empresas de base tecnológica, Allen et al. (2012) destacam que os ganhos líquidos excedem os custos do programa. 
as empresas que foram subsidiadas pelo programa israelense com aquelas que tiveram as solicitações negadas. Não se verifica substituição dos gastos privados em P\&D e sim adicionalidade, pois os investimentos privados cresceram a partir da obtenção dos recursos públicos. A conclusão principal aponta resultados positivos para as $\mathrm{PEs}^{7}$ israelenses, embora menores que os obtidos para as grandes empresas. Entretanto, a diferença não apresentou relevância estatística.

González e Pazó (2008) empreendem avaliação similar para empresas industriais espanholas. Os dados referem-se ao período 1990-99 e envolvem uma amostra de 2.214 firmas. Através da utilização de técnicas de matching, a comparação entre empresas contempladas e não contempladas com subsídios à $\mathrm{P} \& \mathrm{D}$ aponta que os gastos públicos contribuem para ampliar os gastos totais de $\mathrm{P} \& \mathrm{D}$, embora não consigam estimular os gastos privados. Ou seja, “(...) firms do not substitute public funds with private R\&D investment, but public funds do not significantly stimulate private expenditures of firms that would carry out R\&D activities in the absence of subsidies."(p. 384).

Entretanto, quando se estabelece as diferenças de porte e setor, são as $\mathrm{PEs}^{8}$ de setores de baixa tecnologia as que apresentaram os resultados mais positivos. Portanto, para as autoras, este resultado mostra que os fundos públicos têm um importante papel para a tomada de decisão destas empresas em investir em P\&D.

Realizado com metodologia semelhante à de González e Pazó (2008), Özçelik e Taymaz (2008) analisam os impactos dos empréstimos e subsídios à $\mathrm{P} \& \mathrm{D}$ para empresas manufatureiras da Turquia no período 1993-2001. Os resultados encontrados são muito semelhantes aos de González e Pazó (2008), dado que para as empresas de pequeno porte o efeito adicionalidade dos gastos públicos foi maior.

Para os países da América Latina, os principais estudos são os que compõem o trabalho de Acevedo e Tan (2010). Foram desenvolvidos estudos de caso de diversos programas de apoio à $\mathrm{P} \& \mathrm{D}$ utilizando uma combinação de PSM com estimadores DiD para o Chile, Colômbia, México e Peru. Embora a variedade de programas considerados na análise e as diferenças entre os países não permitam ge-

\footnotetext{
7 Pequenas empresas são as que possuem menos de 100 empregados.

8 Considera-se o grupo de firmas com menos de 200 empregados.
} 
neralizar os resultados encontrados, os principais indicadores utilizados mostraram que os programas apresentam impactos positivos em diversas categorias de esforço inovativo, mas também em variáveis de desempenho, especialmente crescimento das vendas pós tratamento, resultado comum aos programas analisados dos quatro países.

Alguns estudos procedem a uma avaliação que considera indiretamente a questão do porte ao classificar os subsídios a P\&D em faixas, segundo o montante de recursos concedido. É o caso do trabalho de Görg e Strobl (2007) para firmas irlandesas e o de Aschhoff (2009) para firmas alemãs. O primeiro, através de uma combinação de matching com estimadores $\mathrm{DiD}$, conclui que os subsídios concentrados nas faixas média e grande não apresentaram efeitos de crowding out, mas apenas para a faixa de subsídios menores foi verificada adicionalidade. Aschhoff (2009) utiliza dados do Community Innovation Survey (CIS) e do Direct R\&D Project Funding (DPF), órgão do governo federal alemão, relativos ao período 1994-2005. Em relação à amostra total, os resultados indicam que os gastos públicos estimulam gastos privados, ou seja, verifica-se adicionalidade. Entretanto, quando se consideram diferentes sub-amostras, definidas por empresas frequentemente apoiadas pelos subsídios versus empresas apoiadas pela primeira vez, e por volume de empréstimos, concluise que as empresas frequentemente apoiadas são as que respondem em maior magnitude aos estímulos públicos ("DPF history matters"). Quanto ao tamanho dos empréstimos, a conclusão principal é de que em nenhuma das três faixas ${ }^{9}$ consideradas verifica-se o efeito substituição, embora o efeito adicionalidade só tenha sido verificado para as duas faixas que representam os empréstimos maiores. Isto significa que as empresas que se inserem na faixa de menores subsídios dependem dos mesmos para a continuidade de seus projetos de P\&D. Este resultado diverge do encontrado por Görg e Strobl (2007).

Da contraposição de estudos realizados para países desenvolvidos e em desenvolvimento, e considerando-se as diferenças de porte das empresas, como o fazem Lach (2002) e Görg e Strobl (2007), Özçelik e Taymaz (2008) concluem que as políticas públicas de apoio à $\mathrm{P} \& \mathrm{D}$ apresentam resultados menos ambíguos e mais positivos nos países em desenvolvimento e para as pequenas empresas: "these

9 Small grants são definidos como os inferiores à 37.200 euros, enquanto a maior faixa é a de empréstimos superiores à 99.000 euros. 
findings may suggest that public $R \& D$ support is likely to play a more important role in stimulating private $R \& D$ in 'late industrializing' countries and/or small firms. The impact could diminish as the firms learn more about $R \& D$ activities."(p. 271).

Avaliações que consideram o porte das empresas contempladas por políticas públicas, mas que analisam programas com desenhos mais específicos são encontradas nos estudos de Chandler (2012), que analisa os impactos do Canada Small Business Financing Program, direcionado ao financiamento de garantias aos empréstimos bancários de empresas com menos de 500 empregados; e o de Arráiz et al. (2013), que analisa o impacto do programa de apoio à formação de redes de fornecedores de pequenas e médias empresas (Programa de Desarrollo de Proveedores).

Portanto, considerando-se os resultados dos estudos apresentados, há evidências de que os benefícios dos programas de apoio à inovação são encontrados também quando se concentram em empresas de pequeno porte, o que vai ao encontro dos resultados obtidos por uma ampla revisão dos programas europeus de apoio à P\&D em pequenas empresas de base tecnológica (Revest e Sapio, 2012). A análise de um conjunto de estudos elaborados nos últimos anos para países da União Europeia permitiu aos autores concluírem que " $R \& D$ tax incentives and public venture capital seem to have produced beneficial effects" (p. 198).

Para o Brasil, são ainda bastante escassos os trabalhos que se propõem a analisar os efeitos das políticas públicas de apoio à $\mathrm{P} \& \mathrm{D}$. Os trabalhos existentes que utilizam técnicas econométricas para realizar análise de impacto não consideram a questão do porte das empresas. Nesta linha, os principais estudos são os desenvolvidos por Avellar (2008, 2009), De Negri et al. (2008) e Araújo et al. (2012). Avellar e Alves (2008), ao avaliar os efeitos do PDTI, concluem que os subsídios do programa induziram as empresas a dobrarem seus investimentos em $\mathrm{P} \& \mathrm{D}$, resultado semelhante ao encontrado por Almus e Czarnitzki (2003) para o caso alemão. Em outro estudo, Avellar (2009) também rejeita a hipótese de crowding out, e conclui que o conjunto de programas analisados contribui para aumentar os gastos privados em $\mathrm{P} \& \mathrm{D}$. 
A análise de um programa, o Programa de Apoio ao Desenvolvimento Tecnológico da Empresa Nacional (ADTEN), realizada por De Negri et al. (2008), também encontrou resultados positivos para as empresas que participaram do programa, sobretudo as relacionadas ao aumento dos gastos de $\mathrm{P} \& \mathrm{D}$ e das vendas das empresas contempladas. Na mesma direção, o estudo realizado por Araújo et al. (2012) sobre os efeitos dos Fundos Setoriais permitiu aos autores rejeitar a hipótese de crowding out. Encontrou-se resultados positivos oriundos do acesso aos Fundos para as variáveis pessoal ocupado e esforços tecnológicos (medido pela taxa de crescimento do pessoal técnico científico ocupado, como variável proxy), embora não se tenha verificado o mesmo comportamento para as exportações.

Outra linha de análise encontra-se no estudo de Salles Filho et al. (2011), que realiza uma comparação entre os resultados do PIPE (Programa de Apoio à Inovação em Pequenas Empresas), programa implementado pela FAPESP (Fundação de Apoio à Pesquisa em São Paulo) com os encontrados para o SBIR. A despeito de diferenças no ambiente institucional no qual os programas são implementados, os resultados mostram semelhanças importantes, em termos de sua capacidade de estimular a geração de novos produtos e processos nas empresas alvo, as pequenas empresas de base tecnológica.

Considerando-se estes resultados, a presente proposta tem como objetivo contribuir para a literatura sobre o tema sob dois aspectos: ao avaliar o impacto de políticas de fomento à inovação de pequenas empresas no Brasil, identificando se o gasto público é capaz de estimular o gasto privado em atividades inovativas; e ao analisar os efeitos de múltiplos instrumentos de políticas de inovação sobre os gastos em atividades inovativas do grupo de pequenas empresas. Para isso, será realizada uma avaliação de impacto das empresas beneficiárias de diversos programas de incentivo à inovação, como apresenta a Pesquisa de Inovação Tecnológica (PINTEC). A análise dos efeitos das políticas considerando-se os diversos programas ainda é pouco tratada na literatura de referência. Dentre os trabalhos citados, apenas parte dos que compóem o estudo de Acevedo e Tan (2010) apresentam os resultados por programa de apoio, tal como realizado neste trabalho. A vantagem desta opção metodológica é a de permitir identificar a contribuição conjunta e em separado dos programas e, portanto, as diferenças de impacto sobre o segmento das PEs. 
A metodologia do estudo e os resultados são apresentados nas seções 4 e 5, respectivamente. A seção seguinte dedica-se a apresentar, sucintamente, a evolução das políticas públicas para as pequenas empresas brasileiras.

\section{Evolução das políticas públicas para pequenas empresas no Brasil}

Embora se possam identificar medidas de apoio às empresas de pequeno porte brasileiras desde os anos 1970, é somente nos anos 1990 que se inicia a construção de um aparato político institucional mais articulado de apoio a este segmento empresarial. A principal mudança neste período situa-se na criação do SEBRAE (Serviço Brasileiro de Apoio às Micro e Pequenas Empresas), órgão paraestatal que passa a atuar junto às micro e pequenas empresas brasileiras. Amplia-se de forma importante o atendimento a este segmento empresarial, e temas fundamentais como a formação de redes e inovação tecnológica, passam a fazer parte da agenda desta instituição. ${ }^{10}$

As políticas públicas voltadas às PMEs ampliam-se nos anos 2000, a partir da definição da Política Industrial, Tecnológica e de Comércio Exterior (PITCE) e de mudanças na legislação.

Dentre os objetivos prioritários da PITCE estavam o aumento da eficiência da estrutura produtiva, o aumento da capacidade de inovação das empresas brasileiras e a expansão das exportações. No documento da PITCE há uma referência explícita à necessidade de considerar a especificidade da inserção de PEs, assim como dos arranjos produtivos locais na estrutura produtiva. Alguns novos instrumentos, especialmente na área de financiamento, foram definidos mas, segundo avaliação de Cano e Silva (2010), não tiveram efeitos significativos nos primeiros anos de implementação.

Para Suzigan e Furtado (2006), as principais deficiências da PITCE estão relacionados aos efeitos adversos da política macroeconômica, sobretudo pelos juros elevados e instabilidade cambial; à falta de

${ }^{10}$ Para uma síntese das políticas públicas voltadas às empresas de pequeno porte brasileiras nas décadas anteriores, ver Naretto et al. (2004). Para o período recente, consultar Matos e Arroio (2011). 
articulação dos instrumentos da política industrial e destes com as demandas das empresas; à precariedade da infraestrutura econômica, em especial devido às incertezas em torno do papel das parcerias público-privadas e das dificuldades de se estabelecer uma institucionalidade adequada aos investimentos em infraestrutura; às insuficiências do sistema de C,T\&I, em função dos poucos recursos direcionados e das dificuldades de mover o aparato institucional para as novas demandas que a política industrial impõe; e, por fim, à fragilidade de comando e coordenação do processo da PI. Este último aspecto relaciona-se à criação da Agência Brasileira de Desenvolvimento Industrial (ABDI), para ser o órgão condutor da política industrial que, criada como serviço social autônomo dentro do "Sistema S", encontra dificuldades de coordenar a ampla gama de Conselhos, Ministérios e órgãos públicos e privados que têm nas suas esferas de ação os instrumentos da PI.

Em relação às PEs, os autores destacam as fragilidades da PITCE relacionadas à questão fiscal, sobretudo a alta carga tributária, a burocracia associada aos empreendimentos e a falta de rigor na fiscalização de práticas fiscais e trabalhistas irregulares. Acentuam ainda as dificuldades de a PI focalizar nas reais demandas dessas empresas como, por exemplo, instrumentos de facilitação dos sistemas de gestão.

A continuidade na implementação da PI deu-se com a Política de Desenvolvimento Produtivo (PDP) em 2008. Embora vários problemas identificados na PITCE tenham sido revistos no âmbito da PDP, pode-se dizer que as principais fragilidades identificadas por Suzigan e Furtado (2006) permaneceram, especialmente o frágil comando político. ${ }^{11}$

Para as PEs, os objetivos tornam-se mais explícitos, na medida em que dentre as quatro macrometas definidas para o período 20082010, uma refere-se ao aumento do número de PMEs exportadoras. Este objetivo não foi alcançado, segundo avaliação da Agência Brasileira de Desenvolvimento Industrial, em virtude dos efeitos da crise internacional. Entretanto, o objetivo permanece como uma das sete metas estabelecidas para o período 2011-14 (Cano e Silva, 2010).

${ }^{11}$ Os autores aprofundam a análise da recente política industrial brasileira em Suzigan e Furtado (2010). 
Em relação às mudanças na legislação, o destaque principal é a Lei de Inovação, aprovada em 2004, cujo objetivo principal é o de estimular a inovação através de novos instrumentos, como a subvenção econômica, e a eliminação de gargalos institucionais à cooperação público-privada.

A legislação sofre alterações ainda com a Lei do Bem, de 2005, que dispõe sobre incentivos fiscais a gastos de P\&D, e a Lei de Informática, criada em 1991 e modificada em 2001, que prevê a redução de IPI como contrapartida aos gastos em P\&D. Em 2006, 130 empresas receberam benefícios previstos pela Lei do Bem, 542 empresas em 2009 e 767 empresas em 2011, representando um crescimento de 490\% no período 2006-11. Destaca-se também que o investimento em $\mathrm{P} \& \mathrm{D}$ das empresas beneficiárias pela Lei do Bem se ampliou de 2,4 bilhões ${ }^{12}$ em 2006, para 8,1 bilhões em 2008 (MCT, 2010). Mesmo diante desse acentuado crescimento, a maior parte das empresas beneficiadas por esse instrumento são grandes empresas, pelo fato de serem lucrativas e por já realizarem previamente atividades de $P \& D$.

A partir da conjugação de mudanças na legislação, aumento orçamentário e pioneirismo na implantação de programas voltados à inovação tecnológica em empresas, a FINEP instituiu, nos anos 2000, diversos programas direcionados ao financiamento à inovação em PEs, tanto com recursos reembolsáveis, quanto com recursos de subvenção econômica. Operados com recursos de subvenção econômica, destacamse o Primeira Empresa Inovadora (PRIME), voltado a empresas nascentes; o Subvenção Econômica; e o Programa de Apoio à Pesquisa em Empresas (PAPPE), direcionado para micro e pequenas empresas e operado a partir das Fundações de Apoio à Pesquisas estaduais. ${ }^{13}$ Com recursos reembolsáveis, a FINEP instituiu também novos programas nos anos 2000, que tentam contribuir para a melhoria das condições de financiamento das empresas nacionais. São exemplos o Programa Juro Zero, sem exigência de garantias reais e voltado a setores de tecnologia avançada, e o Projeto INOVAR, com foco no desenvolvimento de fundos de capital de risco.

\footnotetext{
${ }^{12}$ Em valores de 2008, corrigidos pelo INPC (IBGE - Instituto Brasileiro de Geografia e Estatística).

${ }^{13}$ Matos e Arroio (2011) mostram, por meio de dados do MCT, que os recursos de subvenção têm aumentado nos últimos anos, ademais de ter havido um direcionamento crescente para as micro e pequenas empresas, que obtiveram $63 \%$ do total dos recursos em 2006 e $81 \%$ em 2009.
} 
O maior direcionamento das políticas públicas para o apoio à inovação em PEs também ocorreu por parte do Banco Nacional de Desenvolvimento Econômico e Social (BNDES), que tradicionalmente destinou recursos às grandes empresas nacionais e aos projetos de infraestrutura. Através de um conjunto de novos instrumentos, o Banco tem conseguido aumentar de forma consistente os recursos destinados às PEs e à inovação. Dentre os programas atualmente em execução, destacam-se: Linha Capital Inovador (foco na empresa), Linha Inovação Produção e Linha Inovação Tecnológica (foco no projeto). Estas linhas, abrigadas no programa BNDES Finem, tiveram seus valores de referência alterados para que haja direcionamento à inovação tecnológica em PEs.

Em síntese, mudanças importantes ocorreram nos últimos anos no aparato político-institucional de apoio à inovação em empresas de pequeno porte brasileiras. Estas se consubstanciam em um novo regime de incentivos fiscais (Lei do Bem), em novos programas de apoio financeiro (através da FINEP e BNDES, principalmente) e em estímulos às parcerias entre empresas e outros agentes do sistema de inovações, em particular as universidades e centros de pesquisa (FINEP, SEBRAE e instituições de cunho estadual).

A análise dos impactos dos programas voltados ao apoio às atividades inovativas das empresas de pequeno porte brasileiras é o tema da seção seguinte, que constitui o núcleo do presente artigo.

\section{Metodologia}

A estratégia empírica do trabalho é dividida em duas etapas e utiliza a base de dados da edição da PINTEC, que compreende o período 2006-2008, divulgada pelo IBGE em 2010 (PINTEC, 2010). A primeira etapa baseia-se em estatística descritiva e tem como objetivo caracterizar o perfil das pequenas empresas inovadoras contempladas e não contempladas pelos diferentes programas de apoio à inovação em execução no Brasil, considerando um conjunto amplo de variáveis (Quadro 1). A segunda etapa tem como objetivo compreender os efeitos das políticas de inovação sobre o indicador de esforço inovador, os gastos com atividades inovativas. Para isso, serão estimados modelos econométricos, utilizando-se a técnica do Propensity Score 
Matching. Para a realização desse estudo empírico e o acesso aos microdados da PINTEC, utilizou-se a sala de sigilo na sede do IBGE no Rio de Janeiro.

Inicialmente, é necessário esclarecer que para o estudo proposto serão consideradas as "empresas que implementaram inovação" definidas como as "empresas industriais com 10 ou mais pessoas ocupadas, que implementaram produto e/ou processo tecnologicamente novo ou substancialmente aprimorado, que desenvolveram projetos que foram abandonados ou ficaram incompletos, e que realizaram mudanças organizacionais e/ou de marketing" (PINTEC, 2010, p.64). ${ }^{14}$

A primeira etapa consiste em apresentar, por meio de estatística descritiva, utilizando-se de dados da PINTEC (2010), as características das pequenas empresas, destacando as diferenças e semelhanças entre os grupos de empresas que receberam e o grupo que não recebeu apoio do governo para inovação. O grupo de empresas contempladas é constituído pelas empresas de pequeno porte que responderam "1Sim" para ao menos uma das questões 157, 158,159, 160, 161 e 162, constituintes do questionário da PINTEC (2010). Para cada um desses grupos de pequenas empresas (beneficiadas e não beneficiadas) serão analisadas as médias, desvio padrão e frequência, apresentadas no Quadro 1.

${ }^{14}$ Foi considerado o conjunto de empresas da indústria de transformação que possuem de 10 a 99 empregados, que são as micro e pequenas empresas, segundo classificação do SEBRAE. 
Quadro 1 - Lista de Variáveis

\begin{tabular}{|c|c|}
\hline Variável & Descrição \\
\hline Pessoal Ocupado & Número de pessoas ocupadas na empresa \\
\hline Idade & Calculado pela diferença entre 2008 e o ano de fundação da empresa. \\
\hline $\begin{array}{l}\text { Receita Líquida de } \\
\text { Vendas(RLV) }\end{array}$ & Receita Líquida de Vendas \\
\hline Produtividade do Trabalho & Relação entre Valor de Transformação Industrial e pessoal ocupado \\
\hline Gastos P\&D & Soma das atividades internas e externas de P\&D, exclusivamente \\
\hline $\begin{array}{l}\text { Gastos Atividades } \\
\text { Inovativas }\end{array}$ & Soma das atividades inovativas: Questões 31, 32, 33, 34, 35, 36 e 37. \\
\hline Skill & $\begin{array}{l}\text { Proporção de funcionários com } 3^{\circ} \text { Grau completo (Soma das Questões } \\
46,47 \text { e } 48 \text { ) em relação ao total de pessoal ocupado da empresa: }\end{array}$ \\
\hline Gastos P\&D/RLV & $\begin{array}{l}\text { Soma das atividades internas e externas de P\&D, exclusivamente: } \\
\text { Questões } 31 \text { e } 32 \text { dividida pela Receita Líquida de Vendas. }\end{array}$ \\
\hline $\begin{array}{l}\text { Gastos Atividades } \\
\text { Inovativas/RLV }\end{array}$ & $\begin{array}{l}\text { Soma das atividades inovativas: Questões } 31,32,33,34,35,36 \text { e } 37 \\
\text { dividida pela Receita Líquida de Vendas }\end{array}$ \\
\hline Market share & $\begin{array}{l}\text { Participação da Receita Líquida de Vendas das empresas sobre a Re- } \\
\text { ceita Líquida de Vendas total do setor de atividade econômica, definido } \\
\text { a partir de três dígitos da CNAE. }\end{array}$ \\
\hline Multinacional & $\begin{array}{l}\text { Capital controlador da empresa estrangeiro e/ou misto (nacional e es- } \\
\text { trangeiro) (Questão 01) }\end{array}$ \\
\hline Inovação Organizacional & $\begin{array}{l}\text { Soma das respostas da Questão 188, 189, 190, } 191 \text { e } 192 \text {. Inserir o } \\
\text { valor } 1 \text { para as empresas que responderem } 1 \mathrm{em} \text { ao menos uma dessas } \\
\text { cinco questões. }\end{array}$ \\
\hline Patente & $\begin{array}{l}\text { Soma das respostas da Questão } 163 \text { e } 164 \text {. Inserir o valor } 1 \text { para as } \\
\text { empresas que responderem } 1 \text { em ao menos uma dessas duas questões. }\end{array}$ \\
\hline Exporta & Empresa obtém parte da receita de vendas com exportação. \\
\hline P\&D Contínuo & Empresa que realiza atividades de P\&D de maneira contínua. \\
\hline Bx.Média Tecnologia & $\begin{array}{l}\text { Empresa atua em setor de baixa ou média intensidade tecnológica } \\
\text { (CNAE } 10,11,12,13,14,15,16,17,18,19,22,23,24,31 \text { e } 32 \text { ). }\end{array}$ \\
\hline Regiões Geográficas & $\begin{array}{l}\text { Agrupamento das empresas de cada Unidade da Federação em } 5 \\
\text { regiões geográficas (Sul, Norte, Nordeste, Sudeste e Centro-Oeste). }\end{array}$ \\
\hline
\end{tabular}

Fonte: PINTEC (2010).

$\mathrm{Na}$ segunda parte serão estimados modelos econométricos com a aplicação do Propensity Score Matching (PSM) para a realização da avaliação dos efeitos dos instrumentos de política. A escolha por essa técnica se justifica por se tratar de uma das metodologias mais utilizadas na literatura internacional para avaliação de impacto das políticas de inovação (Almus e Czarnitzki, 2002; Lööf e Hesmati, 2005; Gonzaléz e Pazó, 2008; Özçelik e Taymaz, 2008; Avellar, 2009; Acevedo e Tan, 2010). 
Propensity Score Matching é uma técnica para determinação de quase-experimentos, baseada em algoritmos de pareamento de indivíduos pertencentes a grupos distintos com o objetivo de se julgar os efeitos de um determinado tratamento. Essa metodologia PSM tem sido comumente usada para avaliação de outros programas públicos, que não necessariamente de inovação tecnológica. A técnica consiste na realização de um modelo Probit sobre a variável de classificação das observações e posterior utilização das probabilidades estimadas $\left(\phi\left(X^{\prime} \beta\right)\right)$ para formação do grupo de controle. Conforme apontado por Deheja e Wahba (1998), trata-se da inferência em amostras com viés de seleção em unidades não experimentais onde somente algumas unidades no grupo não experimental são comparáveis com as unidades que receberam o tratamento.

O método PSM, portanto, é constituído das seguintes etapas: (1) Primeiro, realizou-se o teste $\boldsymbol{t}$ de comparação de médias entre as firmas beneficiárias do tratamento e as firmas não beneficiárias dos programas, mas que tenham implementado algum tipo de inovação, segundo PINTEC (2010, p.64); (2) numa segunda etapa, realizouse um modelo Probit para construção dos escores $p_{i}$ e $p_{j}$ no grupo (beneficiárias) e controle (não beneficiárias); (3) após a realização do matching, realizou-se novamente o teste $\boldsymbol{t}$ para comparação de médias entre os grupos balanceados.

A aplicação da técnica de matching ${ }^{15}$ resultará na construção de quatro grupos: (1) Firmas contempladas pela política de inovação que não possuem características em comum com nenhuma outra firma (Beneficiárias Singulares); (2) Firmas contempladas pela política de inovação que possuem características em comum com outras firmas não beneficiárias na amostra (Beneficiárias Não Singulares); (3) Firmas não contempladas pela política de inovação que possuem características em comum com outras firmas não beneficiárias na amostra (Não Beneficiárias Não Singulares); (4) Firmas não contempladas pela política de inovação que não possuem quaisquer características em comum com outras firmas beneficiárias na amostra (Não Beneficiárias Singulares). Posteriormente à realização do matching $^{16}$ será realizada uma análise por meio de teste de comparação de médias, e se concentrará nas firmas dos grupos (2) e (3), ou seja, comparação de firmas comparáveis.

${ }^{15} \mathrm{O}$ algoritmo utilizado nesse estudo é o método do vizinho mais próximo.

${ }^{16}$ Ver Deheja e Wahba (1998) para o detalhamento da técnica de matching. 
Com base nesse método de estimação, o modelo proposto por esse estudo será descrito a seguir. As variáveis explicativas selecionadas para o modelo probabilístico foram:

Pessoal Ocupado: Logaritmo do número de pessoas ocupadas na empresa, para capturar o efeito do tamanho da empresa na probabilidade de participar no programa de apoio à inovação.

Multinacional: Dummy para empresas multinacionais, com objetivo de capturar se a origem do capital é importante para explicar a participação da empresa no programa de apoio à inovação.

Exporta: Dummy para empresas que obtém uma parcela da sua receita com exportação, com objetivo de capturar se a inserção internacional das empresas é importante para explicar a participação da empresa no programa de apoio à inovação.

Market Share: Participação da receita da empresa no setor de atividade econômica, como indicador de competitividade nacional. Essa variável também pode ser considerada uma proxy de tamanho da empresa e de poder de mercado ex post.

P\&D Contínuo: Dummy para empresas que realizaram atividades de $\mathrm{P} \& \mathrm{D}$ contínua.

Skill: Proporção de funcionários com $3^{\circ}$ grau completo em relação ao total de pessoal ocupado da empresa.

Baixa e Média Intensidade Tecnológica (BxMedTec): Dummy para empresas que atuam em setores de baixa ou média intensidade tecnológica.

$\alpha_{j}$ : Região de Localização geográfica da empresa.

A variável dependente do modelo probabilístico construída a partir da PINTEC (2010) é a participação da pequena empresa em um programa de apoio à inovação. Verifica-se, assim, a probabilidade de uma pequena empresa ser beneficiada pelos programas de apoio à inovação.

Especificando-se o modelo ajustado na forma:

$$
\begin{gathered}
\Phi^{-1}(\pi)=\beta_{0}+\beta_{1} \operatorname{lnPO}+\beta_{2} \text { Multi }+\beta_{3} \text { Exporta }+\beta_{4} \text { MarketShare }+\beta_{5} \text { P\&DCont }+ \\
\beta_{6} \text { Skill }+\beta_{7} \text { BxMedTec }+\alpha_{j}
\end{gathered}
$$

versus $\Phi^{-1}(\pi)=\beta_{0}$ 
Após a formação do grupo de controle, com a realização do matching, pode-se identificar, pela comparação das médias, se o fato de participar dos programas de fomento à inovação do governo faz com que as pequenas empresas beneficiadas realizem mais gastos em atividades inovativas em relação às empresas de pequeno porte não beneficiadas.

É importante esclarecer que será aplicado o mesmo modelo, apresentado anteriormente, em nove amostras de pequenas empresas desagregadas pelos instrumentos de apoio à inovação em execução no país, como descrito no Quadro 2.

Quadro 2 - Descrição das Amostras de Pequenas Empresas

\begin{tabular}{|c|c|c|}
\hline Amostra & Descrição & $\begin{array}{l}\text { Número de } \\
\text { Empresas }\end{array}$ \\
\hline Apoio & $\begin{array}{l}\text { Amostra conjunta de todas as PEs que se beneficiaram ao menos de } \\
\text { um programa de apoio à inovação. }\end{array}$ & 737 \\
\hline Incentivos Fiscais & $\begin{array}{l}\text { Amostra de PEs que se beneficiaram de um programa de Incentivos } \\
\text { fiscais, incluindo Incentivos Fiscais à P\&D e inovação tecnológica (Lei } \\
\text { no } 8.661 \text { e Cap. III da Lei no 11.196) e Incentivo fiscal Lei de Informática } \\
\text { (Lei no 10.664, Lei no 11.077). }\end{array}$ & 102 \\
\hline Lei do Bem & $\begin{array}{l}\text { Amostra de PEs que se beneficiaram apenas da Lei do Bem ( Incen- } \\
\text { tivos Fiscais à P\&D e inovação tecnológica - Lei no } 8.661 \text { e Cap. III } \\
\text { da Lei ํㅜ 11.196). }\end{array}$ & 39 \\
\hline Lei de Informática & $\begin{array}{l}\text { Amostra de PEs que se beneficiaram apenas da Lei de Informática } \\
\text { ( Incentivo fiscal Lei de Informática (Lei no } 10.664 \text {, Lei no 11.077)) de } \\
\text { apoio à inovação. }\end{array}$ & 81 \\
\hline Incentivos Financeiros & $\begin{array}{l}\text { Amostra de PEs que se beneficiaram de um programa de incentivo fi- } \\
\text { nanceiro (financiamento) de apoio à inovação, incluindo financiamento } \\
\text { a projetos de P\&D e inovação tecnológica com ou sem parceria com } \\
\text { universidades ou institutos de pesquisa; financiamento exclusivo para } \\
\text { a compra de máquinas e equipamentos utilizados para inovar; bolsas } \\
\text { oferecidas pelas fundações de amparo à pesquisa, RHAE/ CNPq para } \\
\text { pesquisadores em empresas e Aporte de capital de risco. }\end{array}$ & 489 \\
\hline Projetos com Parceria & $\begin{array}{l}\text { Amostra de PEs que se beneficiaram de um programa de incentivo } \\
\text { financeiro (financiamento) a projetos de } P \& D \text { e inovação tecnológica } \\
\text { em parceria com universidades ou institutos de pesquisa. }\end{array}$ & 39 \\
\hline $\begin{array}{l}\text { Máquinas e Equipa- } \\
\text { mentos }\end{array}$ & $\begin{array}{l}\text { Amostra de PEs que se beneficiaram de um programa de incentivo } \\
\text { financeiro (financiamento) exclusivo para a compra de máquinas e } \\
\text { equipamentos utilizados para inovar. }\end{array}$ & 428 \\
\hline Programa RHAE & $\begin{array}{l}\text { Amostra de PEs que se beneficiaram de um programa de Bolsas ofe- } \\
\text { recidas pelas fundações de amparo à pesquisa e RHAE/ CNPq para } \\
\text { pesquisadores em empresas. }\end{array}$ & 19 \\
\hline Capital de Risco & $\begin{array}{l}\text { Amostra de PEs que se beneficiaram de um programa de Aporte de } \\
\text { capital de risco. }\end{array}$ & 24 \\
\hline
\end{tabular}

Estud. Econ., São Paulo, vol.46, n.3, p.609-642, jul.-set. 2016 
A seção a seguir sistematiza os resultados obtidos a partir das estimações.

\section{Análise dos resultados}

A amostra da PINTEC (2010) utilizada nesse estudo é constituída por 6981 pequenas empresas, sendo 737 beneficiadas por algum dos programas de apoio à inovação analisados (Apoio). Os programas que concentram o maior número de empresas beneficiadas são Incentivos Financeiros (489 empresas), apoio à aquisição de Máquinas e Equipamentos (428 empresas) e Incentivos Fiscais (102 empresas).

As pequenas empresas beneficiadas pelos programas assemelham-se às empresas não beneficiadas em algumas características: possuem, em média, de 37 a 48 funcionários, idade média entre 15 e 19 anos e market share inferior a $2 \%$.

Quanto aos indicadores de desempenho produtivo (receita líquida de vendas e produtividade), as empresas de pequeno porte contempladas pelos programas possuem indicadores superiores aos das empresas não contempladas. A produtividade das empresas que receberam apoio é, em média, de R $\$ 62$ mil por trabalhador, enquanto para a amostra total esse valor é de $\mathrm{R} \$ 51 \mathrm{mil}$ por trabalhador. Considerando a amostra de maneira desagregada por programa as pequenas empresas participantes dos incentivos fiscais possuem produtividade, em média, bem superior $(\mathrm{R} \$ 102$ mil) à produtividade média das empresas que participaram do Programa RHAE (R \$54 mil).

No que se refere aos indicadores de esforço inovativo, verifica-se que as empresas que receberam apoio realizam maiores gastos em $P \& D$ e em atividades inovativas do que as pequenas empresas não beneficiadas. Vale ressaltar que os montantes de gastos em P\&D e em atividades inovativas são superiores nas empresas que foram apoiadas pela Lei do Bem e que receberam recursos para desenvolverem Projetos em Parcerias. Outra variável de esforço inovativo que merece destaque é a variável skill. Observa-se que o grupo de empresas beneficiadas possui um percentual de pessoal ocupado com $3^{\circ}$ grau superior à média das empresas não beneficiadas. Contudo, ao se desagregar por programa, verifica-se uma grande heterogeneidade entre as amostras. 
Enquanto as empresas que participam do Programa RHAE possuem em média $14 \%$ de seus funcionários com ensino superior, nas empresas beneficiadas pelos Incentivos Financeiros de maneira agregada esse percentual se reduz para 2\%. Esse resultado é esperado por se tratar de um programa de bolsas para pesquisadores nas empresas.

Quanto aos indicadores de resultados apresentados na Tabela 1, vê-se que grande parte das empresas da amostra total da PINTEC (2010) realizaram inovação organizacional (60\%), enquanto para as empresas beneficiadas esse percentual é ainda maior (81\%). No que tange à variável patente, enquanto $3,25 \%$ das pequenas empresas não beneficiadas depositaram alguma patente de 2006-2008, 8,82\% das empresas beneficiadas depositaram patentes no referido período. 


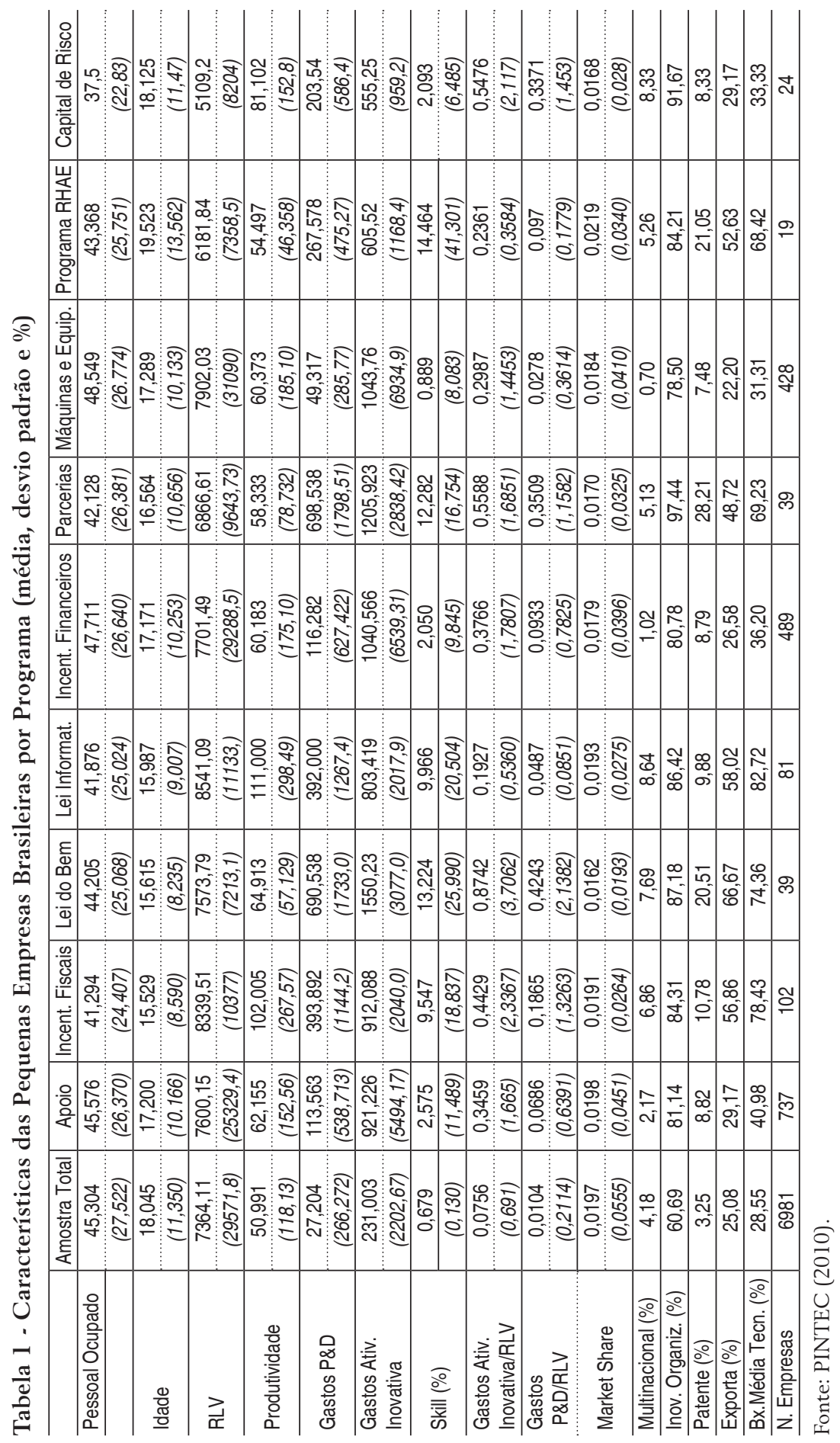


A Tabela 2 apresenta os resultados do teste $\boldsymbol{t}$ para comparação de médias dos gastos com atividades inovativas antes e após a realização do matching. A apresentação dos resultados do teste $\boldsymbol{t}$ para outras variáveis como multinacional, $\mathrm{P} \& \mathrm{D}$ contínuo, market share, skill, exportação e intensidade tecnológica do setor industrial estão descritos na Tabela 1A, no apêndice.

A partir dos resultados apresentados na Tabela 2, verifica-se que o teste $\boldsymbol{t}$ para comparação das médias dos gastos com atividades inovativas das empresas que foram contempladas e das não contempladas pelos programas, antes do pareamento dos dados, evidencia que grande parte dessas diferenças de médias são positivas e estatisticamente significativas, com exceção do Programa RHAE e Capital de Risco. Esse resultado aponta que as empresas beneficiadas pelos programas realizam maior esforço inovativo (gastos com atividades inovativas) em relação às empresas não beneficiadas. As pequenas empresas beneficiadas gastam com atividades inovativas, em média, R\$921 mil por ano, enquanto as não beneficiadas gastam, em média, apenas $\mathrm{R} \$ 149,53$ mil por ano. Contudo, esse resultado impossibilita alguma conclusão sobre a efetividade dos programas para as pequenas empresas, uma vez que a amostra apresenta problemas de autosseleção.

Com base nos resultados descritos na Tabela 1A, pode-se analisar o comportamento do conjunto de outras variáveis. Observa-se que para as variáveis $\mathrm{P} \& \mathrm{D}$ contínuo, skill e exporta o teste $\boldsymbol{t}$ para comparação das médias das pequenas empresas que foram contempladas e não contempladas pelos programas, antes do pareamento dos dados, mostra que grande parte dessas diferenças de médias são positivas e estatisticamente significativas antes do pareamento dos dados. Para a variável baixa e média intensidade tecnológica do setor industrial a diferença de média é negativa e estatisticamente significativa, representando que as pequenas empresas beneficiadas pelos programas concentram-se menos em setores de baixa e média intensidade tecnológica em relação às não beneficiadas. Ainda em relação aos resultados, cabe ressaltar que, mesmo antes do pareamento dos dados, o teste de comparação de médias para a variável market share não foi significante entre os dois grupos na amostra total e nas desagregadas por programa (Tabela 1A). 
Tabela 2- Teste $\mathrm{t}$ para comparação das médias das contempladas pelos programas em relação às empresas não contempladas antes e após o Matching- 2008

\begin{tabular}{|c|c|c|c|c|c|c|c|c|c|c|}
\hline \multirow[b]{2}{*}{ Programas } & \multicolumn{5}{|c|}{ Antes do Matching } & \multicolumn{5}{|c|}{ Após o Matching } \\
\hline & Benef. & Não Benef. & Dif.Média & & $\mathrm{t}$ test & Benef. & Não Benef. & Dif.Média & & $t$ test \\
\hline Apoio & 921,23 & 149,53 & 771,7 & *** & 9,1 & 921,23 & 409,21 & 512,02 & ** & 2,32 \\
\hline Incentivos Fiscais & 912,09 & 220,9 & 691,19 & ** & 3,15 & 912,09 & 1090,1 & $-178,01$ & & $-0,45$ \\
\hline Lei do Bem & 1550,2 & 223,59 & 1326,61 & $\star \star \star \star ~$ & 3,75 & 1550,2 & 536,6 & 1013,6 & & $-1,05$ \\
\hline Lei de Informática & 803,42 & 224,28 & 579,14 & ** & 2,35 & 803,42 & 947,52 & $-144,1$ & & $-0,49$ \\
\hline Incentivos Financeiros & 1040,6 & 170,02 & 870,58 & *** & 8,47 & 1040,6 & 232,46 & 808,14 & ** & 2,71 \\
\hline Parcerias & 1205,9 & 225,53 & 980,37 & ** & 2,77 & 1205,9 & 978,54 & 227,36 & & 0,43 \\
\hline Máquinas & 1043,8 & 177,92 & 865,88 & *** & 7,91 & 1043,8 & 149,97 & 893,83 & *** & 2,66 \\
\hline Programa RHAE & 605,53 & 229,98 & 375,55 & & 0,74 & 605,53 & 663,26 & $-57,73$ & & $-0,18$ \\
\hline Capital de Risco & 555,25 & 229,88 & 325,37 & & 0,72 & 555,25 & 366,38 & 188,87 & & 0,71 \\
\hline
\end{tabular}

Fonte: PINTEC (2010).

O modelo Probit apresentado na Tabela 3 mostra um impacto significativo e positivo das variáveis $\mathrm{P} \& \mathrm{D}$ contínuo e skill, representando que essas variáveis explicam a probabilidade das pequenas empresas participarem dos programas de apoio à inovação. A variável baixa e média intensidade tecnológica apresenta coeficiente associado negativo e estatisticamente significativo, o que significa que ser de setor de baixa e média intensidade tecnológica diminui a probabilidade da empresa ser beneficiada por algum desses programas de apoio à inovação. A não significância de algumas classes de região de localização mostra que estas não diferem entre si quanto à probabilidade de participação das pequenas empresas nos programas públicos de apoio à inovação. 


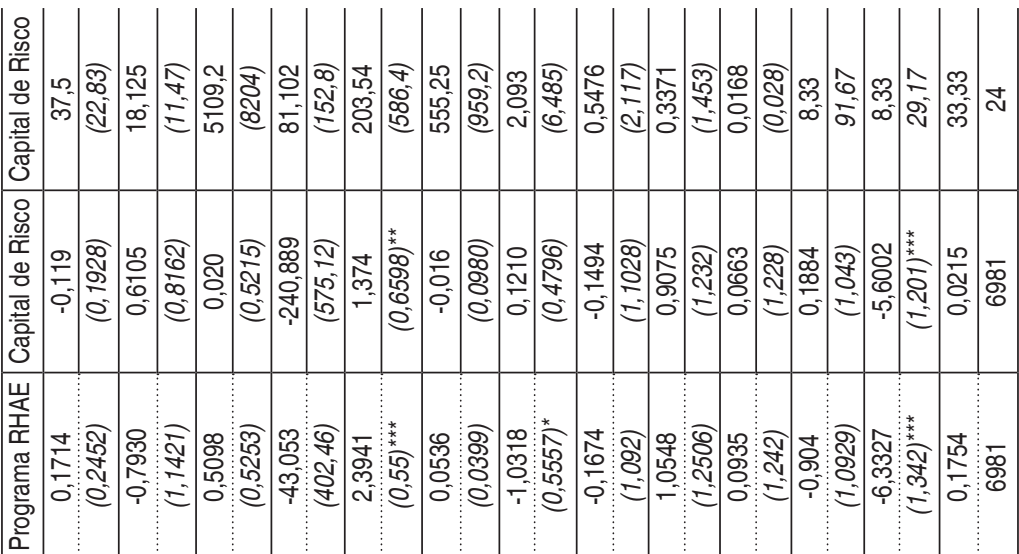

产

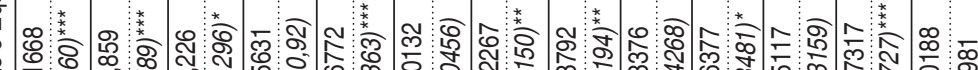
至 $\sum^{\infty}$

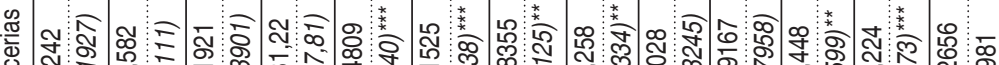
鬲

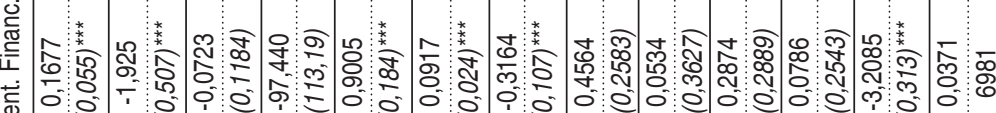

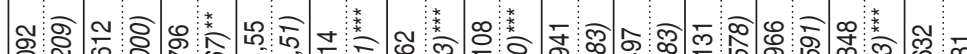
年

\begin{tabular}{|c|c|c|c|c|c|c|c|c|c|c|c|c|c|c|c|c|c|c|}
\hline$\frac{\circ}{\Phi}$ & 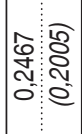 & $\begin{array}{l}0 \\
0 \\
\\
\end{array}$ & & 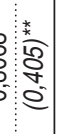 & 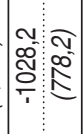 & 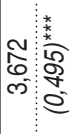 & 㣽 & 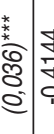 & 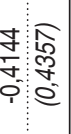 & 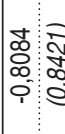 & 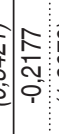 & & $\begin{array}{l}0 \\
0 \\
5 \\
5 \\
0 \\
0\end{array}$ & & & $\begin{array}{l}9 \\
98 \\
98 \\
4\end{array}$ & & : \\
\hline 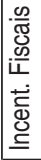 & $\mid \begin{array}{l}0 \\
0 \\
0 \\
0 \\
0 \\
0\end{array}$ & \begin{tabular}{l:c}
$g$ & 0 \\
$N$ & 9 \\
\hdashline & 5
\end{tabular} & 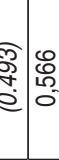 & 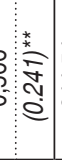 & 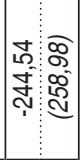 & 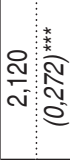 & $\mid$\begin{tabular}{l}
$\frac{\infty}{\sigma}$ \\
\hdashline 0 \\
0
\end{tabular} & ") & 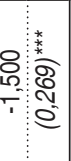 & $\begin{array}{l}1 \\
0 \\
0 \\
m \\
0 \\
0 \\
0\end{array}$ & & & 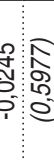 & & $\frac{5}{5}$ & $\begin{array}{l}\frac{8}{6} \\
\frac{6}{6} \\
\end{array}$ & & $\begin{array}{l}5 \\
\mathbf{s} \\
\end{array}$ \\
\hline$\frac{\circ}{\frac{0}{2}}$ & 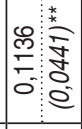 & 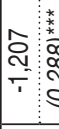 & 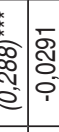 & 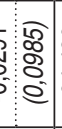 & 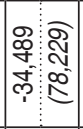 & 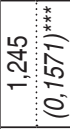 & \begin{tabular}{l} 
\\
$\simeq$ \\
\hdashline 0 \\
0
\end{tabular} & 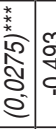 & 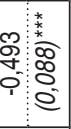 & 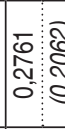 & 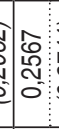 & 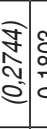 & 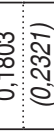 & & న్ & 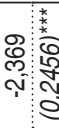 & $\begin{array}{l}1 \\
0 \\
0 \\
0 \\
0\end{array}$ & $\begin{array}{l}\infty \\
5 \\
0\end{array}$ \\
\hline & 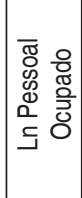 & 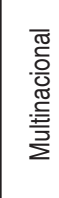 & & $\begin{array}{l}\frac{\pi}{5} \\
\frac{0}{x} \\
\frac{1}{4}\end{array}$ & 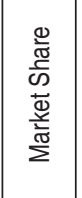 & 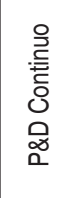 & $\frac{\bar{r}}{c}$ & & $\begin{array}{l}\frac{0}{0} \\
\text { 잉 } \\
\frac{0}{0} \\
\sum_{x}^{\infty}\end{array}$ & 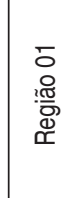 & o & & 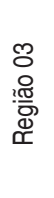 & c & & 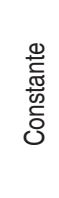 & 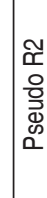 & 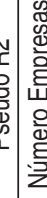 \\
\hline
\end{tabular}


O modelo após a realização do matching, apresentado na Tabela 2, possibilita algumas análises a respeito do efeito dos programas de apoio às pequenas empresas, dado que o conjunto de firmas beneficiárias e não beneficiárias, nesse momento, é comparável.

O teste $\boldsymbol{t}$ para comparação das médias dos gastos com atividades inovativas das empresas contempladas e das não contempladas pelos programas, realizado após o pareamento dos dados, evidencia que essas diferenças de médias são positivas e estatisticamente significativas para os programas analisados em conjunto (Apoio). As empresas beneficiadas por algum dos programas (Apoio) gastam com atividades inovativas $\mathrm{R} \$ 921,23$ mil em média anual, enquanto que as empresas pares não beneficiadas gastam $\mathrm{R} \$ 409,21$ mil em média anual com tais atividades.

Para a amostra agregada de empresas beneficiadas (Apoio) o resultado aponta que os programas de apoio à inovação em execução no Brasil estão sendo efetivos no estímulo aos gastos com atividades inovativas das pequenas empresas beneficiadas. Esse resultado coincide com as evidências encontradas por uma gama de estudos internacionais desenvolvidos recentemente (Lach, 2002, Gonzaléz e Pazó, 2008; Özçelik e Taymaz, 2008; Avellar, 2009; Acevedo e Tan, 2010).

Os outros programas que apresentam diferenças de médias positivas e estatisticamente significativas são os programas de Financiamento e os programas para aquisição de Máquinas e Equipamentos. Quanto ao montante gasto pelas empresas beneficiadas pelos Incentivos Financeiros, observa-se que gastam com atividades inovativas $\mathrm{R} \$ 1040,6$ mil em média anual, enquanto as pequenas empresas pares não beneficiadas gastam somente $\mathrm{R} \$ 232,46$ mil em média anual. Trabalhos como o de Özçelik e Taymaz (2008) encontram evidências sobre a heterogeneidade de resultados em cada instrumento (fiscal ou financeiro) de política implementado.

Entretanto, verifica-se a perda de significância da variável gastos com atividades inovativas em alguns programas de apoio à inovação, tais como Incentivos Fiscais analisados em conjunto e desagregados (Lei do Bem e Lei de Informática). Nota-se que se mantém a ausência de significância para o Programa RHAE e Capital de Risco. 


\section{Considerações finais}

No bojo das mudanças político-institucionais voltadas ao estímulo às atividades inovativas das empresas brasileiras levadas a cabo nos últimos anos, vários programas de apoio com foco em pequenas empresas foram implementados. Realizou-se, neste artigo, análise de impacto destes programas através da técnica econométrica de Propensity Score Matching, em linha com a literatura de referência.

Os programas foram analisados em conjunto e também de forma desagregada, o que permite verificar a efetividade de cada programa de apoio. Na literatura de referência, são encontrados trabalhos que analisam programas específicos mas, em geral, de forma isolada. Portanto, entende-se que a análise dos principais programas que incidem sobre o segmento das empresas de pequeno porte constitui uma importante contribuição deste trabalho para o desenho de políticas públicas.

A amostra da PINTEC 2010 utilizada nesse estudo é constituída por 6981 pequenas empresas, sendo apenas 737 beneficiadas por algum dos programas de apoio à inovação analisados, o que indica um espaço relevante para a atuação das políticas públicas. Os programas que concentram o maior número de empresas beneficiadas são os Incentivos Financeiros (489 empresas), aquisição de Máquinas e Equipamentos (428 empresas) e Incentivos Fiscais (102 empresas).

As pequenas empresas da amostra total e das beneficiadas possuem características semelhantes, mas no que se refere aos indicadores de desempenho produtivo, de esforço e de resultado inovativo, as empresas beneficiadas por algum programa (Apoio) apresentam indicadores superiores à amostra total de empresas. Ressalta-se, entretanto, uma heterogeneidade grande no comportamento desses indicadores em cada amostra desagregada por programa.

Quanto à efetividade dos programas de apoio à inovação às pequenas empresas no Brasil, a partir dos resultados obtidos após a realização do matching, pode-se concluir que os programas de apoio (Apoio) à inovação são efetivos ao serem capazes de estimular o aumento dos gastos com atividades inovativas das pequenas empresas brasileiras. As empresas beneficiadas gastam um montante $125 \%$ superior aos gastos das empresas pares não beneficiadas. 
Ao se analisar os programas de maneira desagregada, vê-se que alguns são mais efetivos do que outros no estímulo aos gastos com atividades inovativas para as pequenas empresas brasileiras, tais como os programas de Financiamentos e os programas de apoio à aquisição de Máquinas e Equipamentos. ${ }^{17}$ Vale ressaltar que a maior diferença de média, cujo teste $\boldsymbol{t}$ foi significativo, encontra-se nos programas de Incentivos Financeiros, em que as empresas beneficiadas gastam um valor 400\% superior ao das empresas pares não beneficiadas. Entretanto, verifica-se também que os programas de Incentivos Fiscais analisados em conjunto e desagregados (Lei do Bem e Lei de Informática), Programa RHAE e o Capital de Risco não se mostraram efetivos no estímulo aos gastos com atividades inovativas superiores das pequenas empresas beneficiadas. ${ }^{18}$

Os resultados encontrados pelo estudo empírico realizado estão em sintonia com os que se verificam em outros países. Embora existam diferenças na definição de pequenas empresas, nas características dos programas em vigência, na forma de avaliá-los (conjunta ou separadamente) e na metodologia utilizada, os resultados, em geral, confirmam a hipótese de adicionalidade dos gastos públicos de apoio às atividades inovativas das empresas beneficiárias dos programas. Esse importante resultado deve ser analisado em trabalhos futuros, de modo a contornar problemas que decorrem do uso da base de dados da PINTEC. Embora a metodologia dessa pesquisa esteja em linha com suas congêneres internacionais, a amostra é enviesada ao considerar apenas empresas inovadoras, que não representam a totalidade da indústria brasileira.

Estudos futuros, que utilizem outras técnicas econométricas, como, por exemplo, método da sobrevivência em dados em painel, podem deixar mais claro o sentido da causalidade, isto é, se são de fato os programas de governo que estimulam as empresas a inovar mais, como o uso do PSM indicou, ou se são as empresas inovadoras que reúnem características que as tornam aptas a captar recursos externos.

\footnotetext{
${ }^{17}$ Diferenças de impacto importantes entre os programas também foram identificadas para os casos do México, Chile e Perú em Acevedo e Tan (2010).

${ }^{18}$ Programas de incentivos fiscais não foram considerados efetivos também na Turquia, conforme indicado por Özçelik e Taymaz (2008).
} 
O estudo apresentado neste artigo também pode ser ampliado em trabalhos futuros que comparem os impactos para empresas de pequeno, médio e grande portes.

\section{Referências}

ACEVEDO, G. L.; TAN, H. W. Impact evaluation of SME programs in Latin America and Caribbean. World Bank, 2010.

ACS, Z. J.; AUDRETSCH, D. B. Innovation and small firms. Cambridge, Massachusetts: MIT Press, 1990.

AERTS, K.; CZARNITZKI, D. Using Innovation Survey Data to Evaluate R\&D Policy: the case of Belgium. ZEW Discussion Paper n. 05-55. Centre for European Economic Research, 2004.

ALLEN, S. D.; LAYSON, S. K.; LINK, A. N. Public gains from entrepreneurial research: inferences about the value of public support of the Small Business Innovation Research Program. Research Evaluation, 21, pp. 105-112, 2012.

ALMUS, M.; CZARNITZKI, D. The Effects of Public R\&D Subsidies on Firms' Innovation Activities: the case of Eastern Germany. ZEW Discussion Paper n. 01-10. Centre for European Economic Research, 2002.

ARRÁIZ, I.; HENRÍQUEZ, F.; STUCCHI, R. Supplier development programs and firm performance: evidence from Chile. Small Business Economics, 41, pp. 277-293, 2013.

ASCHHOFF, B. The effects of subsidies on R\&D investment and success: do subsidy history and size matter? Centre for European Economic Research, ZEW Discussion Paper n. 09-32, 2009.

AUDRETSCH, D. Sustaining innovation and growth: public policy support for entrepreneurship. Industry and Innovation, vol. 11 (3), pp. 167-194, 2004.

AVELLAR, A. P.; ALVES, P. Avaliação de impacto de programas de incentivos fiscais à inovação - um estudo sobre os efeitos do PDTI no Brasil. Revista EconomiA,143-164, 2008.

AVELLAR, A. P. Impacto das Políticas de Fomento à Inovação no Brasil sobre o Gasto em Atividades Inovativas e em Atividades de P\&D das Empresas. Estudos Econômicos, 39, 629-649, 2009.

ARAÚJO, B.C.; PIANTO, D.; DE NEGRI, F.; CAVALCANTE, L. R.; ALVES, P. F. Impactos dos fundos setoriais nas empresas. Revista Brasileira de Inovação, Vol. 11(Número especial), pp. 85-111, 2012.

BAUM, C. An Introduction to Modern Econometrics Using Stata. Stata Press Publication, United States, 2006.

BECKER, S.; ICHINO, A. Estimation of Average Treatment Effects based on Propensity Scores. The Stata Journal, 2, 4, 358-377, 2002.

BENAVENTE, J. M.; CRESPI, G.; MAFFIOLI, A. Public support to firm level innovation: an evaluation of the FONTEC program. Revista Brasileira de Inovação, Vol. 11(Número especial), pp. 113-152, 2012.

BLOOM, N.; GRIFFITH, R.; VAN REENEN, J. Do R\&D Tax Credit work? Evidence form a panel of countries 1979-1997. Journal of Public Economics, n.85, pp.01-31, 2002.

BLUNDELL, R.; DIAS M.C. Alternative approaches to evaluation in empirical microeconomics. Working paper CWP 26/08. The Institute for Fiscal Studies, Centre for Microdata methods and practice, 2008.

CHANDLER, V. The economic impact of the Canada small business financing program. Small Business Economics, 39, pp. 253-264, 2012.

Estud. Econ., São Paulo, vol.46, n.3, p.609-642, jul.-set. 2016 
CANO, W.; SILVA, A. L. G. Política industrial do governo Lula. Texto para Discussão no. 181, IE/ Unicamp, 2010.

COMANOR, W. S. Market structure, product differentiation, and industrial research. Quarterly Journal of Economics, vol. 81, pp. 639-657, 1967.

COHEN, W. M.; LEVIN, R. C.; MOWERY, D. C. Firm size and R\&D intensity: A Re-examination. The Journal of Industrial Economics, vol. 35, pp. 543-565, 1987.

CZARNITZKI, D.; HANEL, P.; ROSA, J. M. Evaluations the Impact of R\&D Tax Credits on Innovation: a Microeconometric Study on Canadian Firms. Centre for European Economic Research, ZEW Discussion Paper n. 04-77, November, 2004.

DAVID, P. A.; HALL, B. H.; TOOLE, A.A. Is public R\&D a complement or substitute for private R\&D? A review of the econometric evidence. Research Policy, n.29, pp.497-529, 2000.

DE NEGRI, J. A; DE NEGRI, F.;LEMOS, M. B. O impacto do programa ADTEN sobre o desempenho e o esforço tecnológico das empresas industriais brasileiras. DE NEGRI, J. A.; DEHEJA, R. H.; WAHBA, S. Propensity Score Matching Methods for Non-Experimental Causal Studies. National Bureau of Economic Research. Working Paper Series 6829, 1998.

DINI, M.; STUMPO, G. Políticas para la innovación en las pequeñas y medianas empresas en América Latina, Nações Unidas, Chile, 2011.

ELSTON, J.A.; AUDRETSCH, D. Financing the entrepreneurial decision: an empirical approach using experimental data on risk attitudes. Small Business Economics, 36, pp. 209-222, 2011.

EUROSTAT. Key figures on European business with a special feature on SMEs. Eurostat Pocket Books. Luxembourg: Publications Office of the European Union, 2011.

FERRARO, C, (Org.) Apoyando a las pymes: Políticas de fomento en América Latina y el Caribe. Nações Unidas, Chile, 2011.

GONZÁLEZ, X.; PAZÓ, C. Do public subsidies stimulate private R\&D spending? Research Policy 37, pp. 371-389, 2008.

GÖRG, H., STROBL, E. The effect of R\&D subsidies on private R\&D. Economica 74, pp. 215-234, 2007.

HALL, B.H.; VAN REENEN, J. How effective are fiscal incentives for R\&D? A review of the evidence. Research Policy, 29, pp.449-469, 2000.

KLEINKNECHT, A.; REIJNEN, J. O. N. More evidence on the undercounting of small firm R\&D. Research Policy, vol. 20, pp. 579-587, 1991.

LACH, S. Do R\&D subsidies stimulate or displace private R\&D? Evidence from Israel. Journal of Industrial Economics 50, pp. 369-390, 2002.

LERNER, J. The Government as Venture Capitalist: The Long-run effects of the SBIR Program, Journal of Business 72, pp. 285-318, 1996.

LEYDEN, D. P.; LINK, A. N. Tax policies affecting R\&D: an international comparison. Technovation, n.13, pp. 17-25, 1993.

LÖÖF, H.; HESMATI, A. The Impact of Public Funding on Private R\&D investment: new Evidence from a Firm Level Innovation Study. CESIS Working Paper Series, n. 6, 2005.

LUNDVALL, B-A.; BORRÁS, S. Science, Technology, and Innovation Policy. The Oxford Handbook of Innovation, Oxford: Oxford University Press, pp. 599-631, 2006.

MATOS, M.; ARROIO, A. Políticas de apoio a micro e pequenas empresas no Brasil: Avanços no período recente e perspectivas futuras. Nações Unidas, Chile, 2011.

NARETTO, N.; BOTELHO, M.R.A.; MENDONÇA, M. A trajetória das políticas públicas para pequenas e médias empresas no Brasil: do apoio individual ao apoio a empresas articuladas em arranjos produtivos locais. Planejamento e Políticas Públicas, n.27, pp. 61-115, 2004.

OECD. Small and Medium-sized Enterprises: Technology and Competitiveness. Paris: OCDE Publications, 1993. 
OECD. The OECD Innovation Strategy: Innovation to Strengthen Growth and Address Global and Social Challenges. Paris: OCDE Publications, 2010.

ÖZÇELIK, E.; TAYMAZ, E. R\&D support programs in developing countries: the Turkish experience. Research Policy 37, pp. 258-275, 2008.

PINTEC. Pesquisa de Inovação Tecnológica - 2008. Rio de Janeiro, IBGE, 2010.

REVEST, V.; SAPIO, A. Financing technology-based small firms in Europe: what do we know? Small Business Economics, 39, pp.179-205, 2012.

SALLES FILHO, S.; BONACELLI, M.B.; CARNEIRA, A.M.; CASTRO, P.F.D.; SANTOS, F.O. Evaluation of ST\&I programs: a methodological approach to the Brazilian Small Business Program and some comparisons with the SBIR program. Research Evaluation 21, pp. 159-171, 2011.

SANTARELLI, E.; PIERGIOVANNI, R. Analyzing literature-based innovation output indicators: the Italian Experience. Research Policy, vol. 25, pp. 689-711, 1996.

SCHERER, F. M. Firm size, market structure, opportunity, and the output of patented inventions". The American Economic Review, vol. 55, pp. 1097-1125, 1965.

SUZIGAN, W.; FURTADO, J. Política Industrial e Desenvolvimento. Revista de Economia Política, vol. 26, n' 2 (102), pp. 163-185, 2006.

SUZIGAN, W.; FURTADO, J. Instituições e Políticas Industriais e Tecnológicas: Reflexões a partir da Experiência Brasileira. Estudos Econômicos, Vol. 40, no. 1, pp. 7-41, 2010.

TETHER, B.S.; SMITH, I.J.; THWAITES, A.T. Smaller enterprises and innovation in the UK: the SPRU Innovations Database revisited. Research Policy, no. 26, pp. 19-32, 1997.

WALLSTEN, S. The effect of government-industry R\&D programs on private R\&D: the case of the small business innovation research program. Rand Journal of Economics, 1, pp. 82-100, 2000.

WOOLDRIDGE, J.M. Econometric Analysis of Cross Section and Panel Data. The MIT Press, Cambridge, Massachusetts, 2010. 


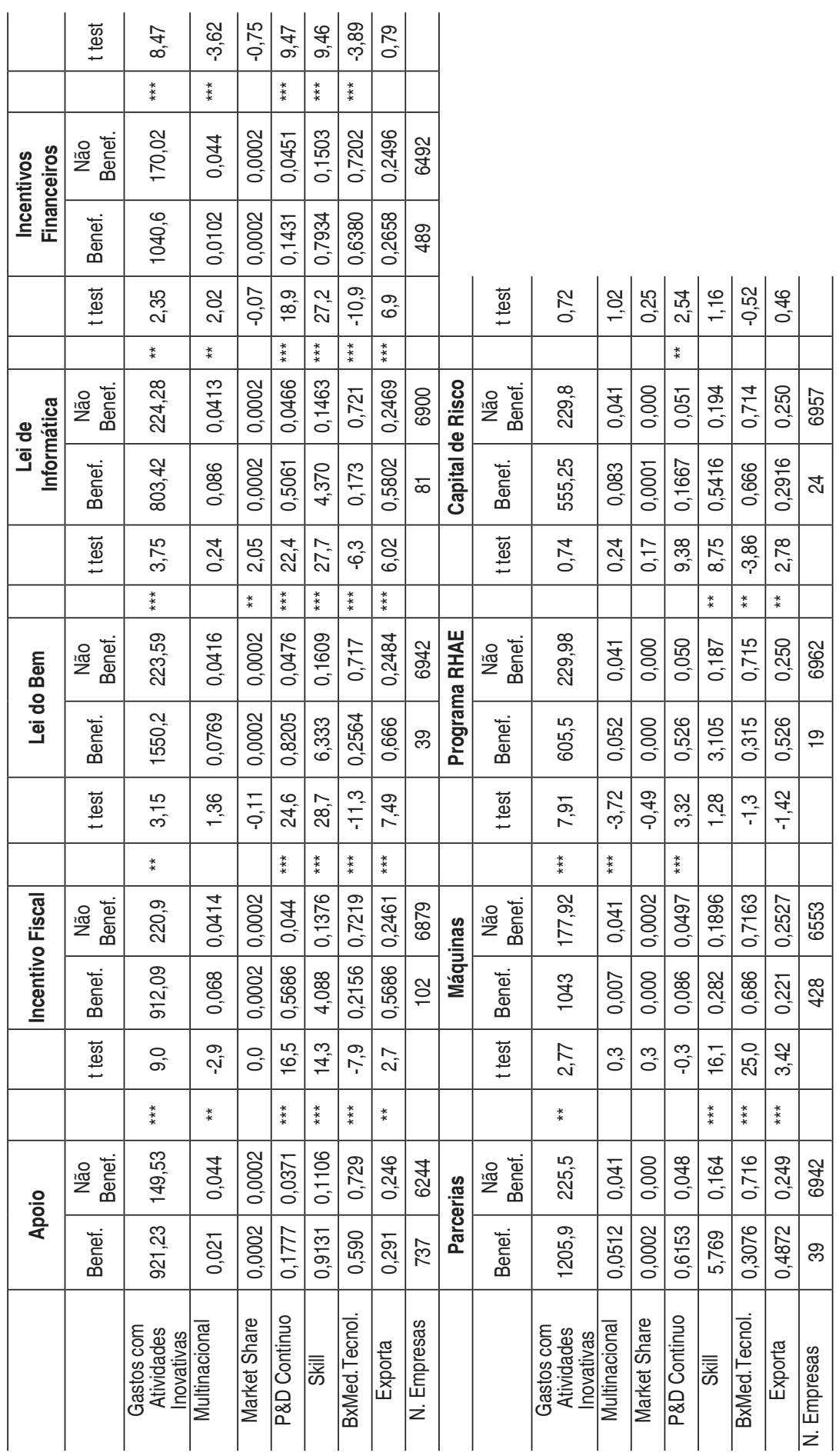




\begin{tabular}{|c|c|c|c|c|c|c|c|c|c|c|c|c|c|c|c|c|c|c|c|}
\hline & $\stackrel{\stackrel{\mathscr{\Phi}}{\leftrightarrows}}{=}$ & $\stackrel{\bar{N}}{\mathrm{~N}}$ & 趈 & 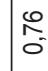 & $\frac{\infty}{0}$ & O & $\sigma^{\circ}$ & $\begin{array}{l}\mathscr{8} \\
0 \\
0\end{array}$ & & & \multirow{5}{*}{\multicolumn{2}{|c|}{$\hat{R}_{0}$}} & \multirow[b]{5}{*}{$\left|\begin{array}{l}0 \\
0 \\
0 \\
1\end{array}\right|$} & \multirow{5}{*}{\multicolumn{2}{|c|}{\begin{tabular}{l}
$\mathfrak{Y}$ \\
\hdashline \\
0
\end{tabular}}} & \multirow[b]{5}{*}{$\left|\begin{array}{c}\hat{f} \\
0 \\
0\end{array}\right|$} & \multirow{5}{*}{\multicolumn{2}{|c|}{ 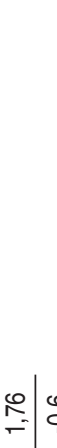 }} & \\
\hline & & $\underset{*}{*}$ & & & & & & & & & & & & & & & & & \\
\hline \multirow{3}{*}{ 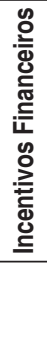 } & 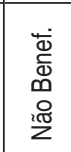 & $\begin{array}{l}\stackrel{9}{\mathcal{N}} \\
\underset{\tilde{N}}{N}\end{array}$ & $\frac{\bar{g}}{\bar{\sigma}}$ & ठ̊ & $\frac{\bar{m}}{\overline{0}}$ & $\begin{array}{l}0 \\
0 \\
0 \\
0 \\
0 \\
0\end{array}$ & 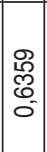 & 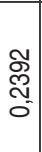 & 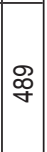 & & & & & & & & & & \\
\hline & $\begin{array}{l}\text { 迎 } \\
\stackrel{\Phi}{\Phi}\end{array}$ & 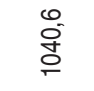 & ণ & ণิ & $\frac{\bar{m}}{\bar{\sigma}}$ & 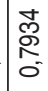 & \begin{tabular}{l|}
$\infty$ \\
0 \\
0 \\
0 \\
0
\end{tabular} & $\begin{array}{l}\infty \\
\stackrel{0}{0} \\
\stackrel{0}{0} \\
0\end{array}$ & 喿 & & & & & & & & & \multirow[b]{2}{*}{\begin{tabular}{l}
0 \\
\hdashline
\end{tabular}} & \\
\hline & 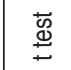 & $\begin{array}{l}\text { g } \\
\text { í }\end{array}$ & $\begin{array}{l}\text { ָ̃ } \\
0 \\
0\end{array}$ & רิ & $\stackrel{0}{0}$ & 苟 & רִ & \begin{tabular}{l}
0 \\
\hdashline \\
$i$ \\
1
\end{tabular} & & & & & & & & & & & \\
\hline \multirow{3}{*}{ 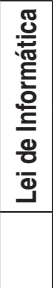 } & 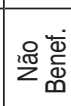 & $\begin{array}{l}\text { No } \\
\text { Fे } \\
\text { Fे }\end{array}$ & $E_{0}$ & ठิ & 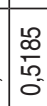 & 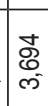 & $\mid \begin{array}{l}\bar{L} \\
\infty \\
\overline{0} \\
\end{array}$ & $\begin{array}{l}\stackrel{2}{0} \\
\stackrel{8}{0} \\
0\end{array}$ & $\infty$ & \multirow{2}{*}{ 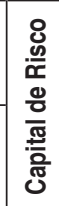 } & 党 & $\begin{array}{l}\infty \\
0 \\
0 \\
0 \\
0\end{array}$ & $\stackrel{\stackrel{2}{N}}{\frac{2}{0}}$ & $\overline{8}$ & 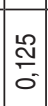 & $\begin{array}{l}\mathscr{2} \\
0 \\
0 \\
0 \\
0\end{array}$ & $\left|\begin{array}{l}8 \\
\stackrel{O}{\sigma} \\
0 \\
0\end{array}\right|$ & $\mid \begin{array}{l}\stackrel{2}{2} \\
0 \\
0 \\
0\end{array}$ & $\stackrel{\sim}{\sim}$ \\
\hline & $\begin{array}{l}\text { 㐫 } \\
\stackrel{\bar{\Phi}}{\Phi} \\
\end{array}$ & 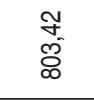 & $\begin{array}{l}\mathscr{0} \\
\mathbb{0} \\
0\end{array}$ & §్ & $\begin{array}{l}\overline{8} \\
0 \\
0 \\
0\end{array}$ & 六 & $\begin{array}{c}\stackrel{2}{N} \\
\stackrel{1}{0} \\
0 \\
0\end{array}$ & 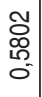 & $\infty$ & & $\begin{array}{l}\text { Ф் } \\
\stackrel{\Phi}{\Phi} \\
\end{array}$ & 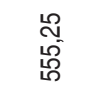 & 总 & 흥 & $\mid \begin{array}{l}\hat{0} \\
6 \\
0 \\
0\end{array}$ & $\begin{array}{l}0 \\
\begin{array}{c}0 \\
0 \\
0 \\
0\end{array}\end{array}$ & $\begin{array}{l}0 \\
0 \\
0 \\
0\end{array}$ & 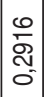 & $\stackrel{\Xi}{\sim}$ \\
\hline & 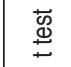 & $\stackrel{2}{\circ}$ & మ్ల & $\frac{1}{c}$ & mo & 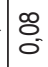 & $\begin{array}{l}\hat{1} \\
0 \\
i\end{array}$ & $\hat{0}$ & & & 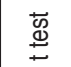 & $\frac{\infty}{c}$ & O & $\underset{-}{g}$ & $\mid \begin{array}{c}\mathbf{T} \\
0 \\
0 \\
0\end{array}$ & $\begin{array}{l}\infty \\
\tilde{c} \\
0\end{array}$ & $\therefore$ & 芯 & \\
\hline \multirow{4}{*}{$\begin{array}{l}\text { 텅 } \\
\text { ๓ } \\
\text { 응 } \\
\bar{\Phi}\end{array}$} & 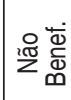 & $\begin{array}{l}0 \\
0 \\
0 \\
0\end{array}$ & $\frac{\widetilde{O}}{0}$ & ठे & $\begin{array}{l}\bar{c} \\
\bar{o} \\
0 \\
0 \\
0\end{array}$ & $\frac{\pi}{0}$ & $\mid$\begin{tabular}{l|}
$\mathscr{O}$ \\
$\mathscr{D}$ \\
0 \\
0 \\
0 \\
0
\end{tabular} & $\begin{array}{l}\hat{\circ} \\
\stackrel{0}{0} \\
0 \\
0\end{array}$ & ஜ & \multirow{2}{*}{ 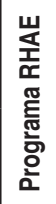 } & 离 & 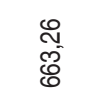 & 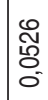 & $\overline{8}$ & 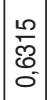 & $\begin{array}{l}\infty \\
\vdots \\
\vdots \\
\sim \\
\sim\end{array}$ & $\mid \begin{array}{l}\hat{1} \\
\underline{\omega} \\
0 \\
0\end{array}$ & $\mid$\begin{tabular}{c}
0 \\
$\stackrel{0}{y}$ \\
\multirow{2}{0}{} \\
0
\end{tabular} & 이 \\
\hline & 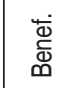 & 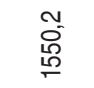 & $\begin{array}{l}\text { o } \\
0 \\
0 \\
0\end{array}$ & §ิ & 오․ & ల్ల & 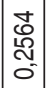 & $\begin{array}{l}\mathscr{6} \\
\varnothing \\
\Xi \\
0\end{array}$ & ஜ্ল & & $\begin{array}{l}\dot{\Phi} \\
\stackrel{\bar{\Phi}}{\Phi}\end{array}$ & 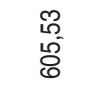 & 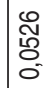 & ণ్ & 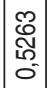 & $\frac{\mathscr{\Omega}}{\stackrel{0}{\circ}}$ & $\mid$\begin{tabular}{c|}
$\frac{1}{n}$ \\
$\frac{m}{0}$ \\
0 \\
0
\end{tabular} & 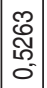 & 임 \\
\hline & 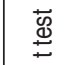 & 年 & $\begin{array}{c}\bar{N} \\
\bar{c}\end{array}$ & $\begin{array}{l}\approx \\
0 \\
0\end{array}$ & 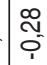 & लू & 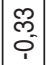 & $\begin{array}{l}\mathscr{0} \\
\mathscr{O} \\
0\end{array}$ & & & 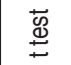 & $\stackrel{8}{i}$ & 8 & 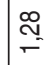 & $\mid \begin{array}{l}0 \\
2 \\
0\end{array}$ & $\begin{array}{l}\sigma \\
\sigma \\
\sigma\end{array}$ & $\begin{array}{c}+ \\
\hat{0} \\
i\end{array}$ & 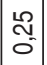 & \\
\hline & & & & & & & & & & & & \begin{tabular}{l|l}
$*$ \\
$*$ \\
$*$
\end{tabular} & & & & & & & \\
\hline \multirow{4}{*}{ 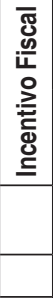 } & 尝 & 홍 & 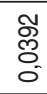 & Оे & $\begin{array}{l}\widetilde{0} \\
\infty \\
\infty \\
0 \\
0 \\
0\end{array}$ & 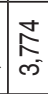 & 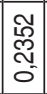 & $\begin{array}{l}8 \\
0 \\
0 \\
0\end{array}$ & ণ & \multirow{2}{*}{$-\frac{9}{\stackrel{0}{5}}$} & 党 & $\begin{array}{l}\hat{\sigma} \\
\text { o } \\
\stackrel{5}{-}\end{array}$ & 흠 & $\overline{8}$ & 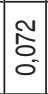 & 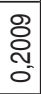 & 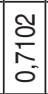 & 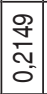 & $\stackrel{\leftrightarrow}{\Im}$ \\
\hline & 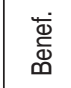 & $\begin{array}{l}8 \\
\stackrel{8}{0} \\
\frac{1}{\sigma}\end{array}$ & $\begin{array}{l}\infty \\
\varnothing \\
0 \\
0\end{array}$ & ठิ & $\begin{array}{l}\mathscr{1} \\
0 \\
0 \\
0 \\
0 \\
0\end{array}$ & $\begin{array}{l}\infty \\
\mathscr{o} \\
\forall \\
\forall\end{array}$ & 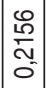 & $\begin{array}{l}\mathscr{0} \\
\& \\
\mathbb{0} \\
0 \\
0\end{array}$ & $\approx$ & & Ф் & $\begin{array}{l}\infty \\
\stackrel{\infty}{o} \\
\stackrel{0}{0}\end{array}$ & 응 & 흥 & $\mid$\begin{tabular}{l|}
$\mathbf{O}$ \\
0 \\
0 \\
0 \\
0 \\
0
\end{tabular} & 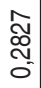 & \begin{tabular}{l|}
8 \\
8 \\
8 \\
0 \\
0 \\
\end{tabular} & 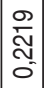 & 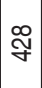 \\
\hline & 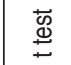 & $\stackrel{\text { ల్ }}{\text { N }}$ & $\stackrel{\tau}{\tau}$ & 0 & ס & O⿱㇒㠯 & \begin{tabular}{|l|} 
\\
0 \\
0 \\
$i$
\end{tabular} & $\frac{0}{\div-}$ & & & 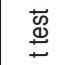 & $\underset{0}{\stackrel{9}{0}}$ & 8 & O & 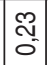 & 年 & \begin{tabular}{|l|} 
\\
2 \\
0 \\
0
\end{tabular} & 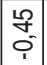 & \\
\hline & & $\stackrel{*}{*}$ & * & & & & & & & & & & & & & & & & \\
\hline \multirow{2}{*}{$\frac{\circ}{\frac{0}{2}}$} & 尝 & $\begin{array}{l}\bar{c} \\
\stackrel{\sigma}{\sigma}\end{array}$ & $\begin{array}{l}\mathscr{8} \\
\bar{\delta} \\
0\end{array}$ & §ิ & 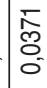 & $\frac{8}{E}$ & $\begin{array}{l}\stackrel{2}{N} \\
0 \\
0\end{array}$ & $\begin{array}{c}\mathscr{Q} \\
\stackrel{\sim}{\sim} \\
\sigma\end{array}$ & $\underset{\mathbb{Z}}{\mathbb{Z}}$ & \multirow{2}{*}{ 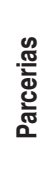 } & 舀 & $\begin{array}{l}\stackrel{0}{0} \\
\infty \\
\sigma \\
\sigma\end{array}$ & $\frac{N}{2}$ & రิ & $\mid$\begin{tabular}{l|}
0 \\
0 \\
0 \\
0 \\
0 \\
0
\end{tabular} & \begin{tabular}{l}
$\bar{\sim}$ \\
$\infty$ \\
\multirow{\sigma}{*}{}
\end{tabular} & 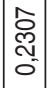 & 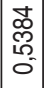 & ஜ্ \\
\hline & 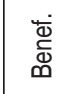 & 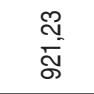 & స్. & ণิ & $\frac{\hat{N}}{\hat{N}}$ & $\bar{c}$ & $\begin{array}{l}8 \\
\text { 足 } \\
0 \\
0\end{array}$ & $\begin{array}{l}\overline{\mathbf{S}} \\
\mathbf{N}\end{array}$ & $\hat{\rho}$ & & 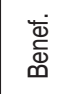 & 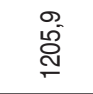 & $\frac{N}{i g}$ & 응 & \begin{tabular}{|l|}
0 \\
0 \\
0 \\
0 \\
0 \\
0
\end{tabular} & $\begin{array}{l}8 \\
0^{\circ} \\
\omega^{\prime}\end{array}$ & \begin{tabular}{|c|}
0 \\
0 \\
0 \\
- \\
0 \\
0
\end{tabular} & 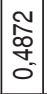 & 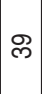 \\
\hline & & 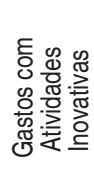 & 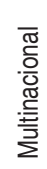 & 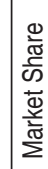 & 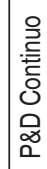 & 言 & 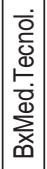 & 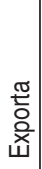 & 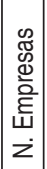 & & & 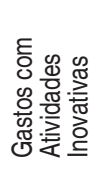 & 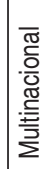 & 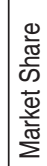 & 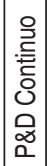 & $\frac{\overline{\bar{z}}}{\omega}$ & 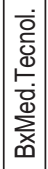 & \begin{tabular}{|l|}
\multicolumn{2}{c}{} \\
$\frac{2}{2}$ \\
x \\
\end{tabular} & 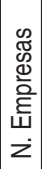 \\
\hline
\end{tabular}

